\title{
Dry Deposition Monitoring Methods in Alberta
}


Digitized by the Internet Archive in 2015 


\title{
Dry Deposition Monitoring Methods in Alberta
}

\author{
Prepared for: \\ Alberta Environment \\ Edmonton, Alberta
}

Final Report

By:

WBK \& Associates Inc.

St Albert, Alberta

March 2006 
ISBN: 978-0-7785-7583-2 (Printed)

ISBN: 978-0-7785-7584-9 (On-line)

Web Site: http://www.gov.ab.ca/env/

Any comments, questions, or suggestions regarding the content of this document may be directed to:

Air Policy Branch

Alberta Environment

11th Floor, Baker Centre

10025-106 Street

Edmonton, $A B$

T5J $1 \mathrm{G} 4$

Fax: (780) 644- 8946

Additional copies of this document may be obtained by contacting:

Information Centre

Alberta Environment

Main Floor, Oxbridge Place

9820 - 106th Street

Edmonton, Alberta T5K 2J6

Phone: (780) 427-2700

Fax: (780) 422-4086

Email: env.infocent@gov.ab.ca 


\section{FOREWORD}

Acid deposition occurs when acidifying pollutants emitted from anthropogenic and other processes undergo chemical reactions in the atmosphere and fall to the earth as wet deposition (rain, snow, cloud, fog) or dry deposition (dry particles, gas). Acidic pollutants can be transported long distances in the atmosphere from their sources and eventually be deposited in ecosystems over broad regional scales and in locations far from the emission sources.

Dry deposition is generally more a local problem than wet deposition. Direct measurement of dry deposition rates is difficult. Dry deposition depends on many factors, including: meteorological conditions, characteristics of the pollutants being deposited (e.g. different gaseous chemical and particle size), and characteristics of the surface on which deposition occurs.

The most accepted and common method for estimating dry deposition is the so-called "inference method." The inferential method is a combination of measurement and modeling that involves indirect estimation of dry deposition rates on the basis of routinely measured air concentrations and meteorological parameters. The method is based on an assumed steady-state relationship $\mathrm{F}=\mathrm{V}_{\mathrm{d}} \mathrm{C}$, where the dry deposition flux or rate $(\mathrm{F})$ is a product of the dry deposition velocity $\left(\mathrm{V}_{\mathrm{d}}\right)$ and the concentration $(\mathrm{C})$ of an airborne pollutant.

A series of studies have been initiated by AENV to evaluate the inference method and search for the most suitable and simple model for deposition rate estimations in Alberta. This report documents the second study in the series. Titles for the reports of the other studies are: "Review and Assessment of Methods for Monitoring and Estimating Dry Deposition in Alberta", and "Refinement Study of Dry Deposition Inference Method Used in Alberta". It is anticipated that once all necessary information is gathered, an Alberta protocol for dry deposition measurement will be prepared.

Lawrence Cheng, Ph. D.

Air Policy,

Climate Change, Air and Land Policy Branch 


\section{SUMMARY}

Currently there is no standard method for field measurement and estimation of dry deposition of acidifying pollutants in Alberta. Alberta Environment is pursuing development of an inexpensive standard method. This may involve a combination of continuous, intermittent, and/or passive field measurements of acidifying pollutants and using inference methods for estimating sulphur and nitrogen species dry deposition. An overall objective of this study was to continue evaluating inferential methods for estimating dry deposition rates.

\section{Dry Deposition Methods Evaluation}

Three different inference methods used in Canada were evaluated for estimating sulphur and nitrogen species dry deposition. These methods were developed by Alberta Environment (AENV), Environment Canada (ENVC), and the Wood Buffalo Environmental Association (WBEA). A specific objective was to use these inference methods to compare contributions of gaseous $\mathrm{SO}_{2}, \mathrm{NO}_{2}, \mathrm{HNO}_{3}, \mathrm{HNO}_{2}$, and particulate forms of sulphur $\left(\mathrm{SO}_{4}{ }^{2-}\right)$ and nitrogen $\left(\mathrm{NO}_{3}{ }^{-}\right.$and $\left.\mathrm{NH}_{4}{ }^{+}\right)$in total sulphur and nitrogen deposition and their potential relationships among each method. Another specific objective was to identify and recommend a preferred method (or methods) that could be routinely used for estimating sulphur and nitrogen species dry deposition rates. The following findings are noted:

1. Complete sulphur and nitrogen gaseous and particulate species and meteorological data for a one-year period (2003) from the Wood Buffalo Environmental Association Fort McKay air monitoring station were evaluated using the three methods. All three methods showed a similar ability to represent variation in dry deposition rates for individual species from month to month.

2. The WBEA method yielded higher monthly deposition rates for most species modeled $\left(\mathrm{SO}_{4}{ }^{2-}, \mathrm{NO}_{2}, \mathrm{HNO}_{3}, \mathrm{HNO}_{2}\right.$, and $\left.\mathrm{NH}_{4}{ }^{+}\right)$compared to the AENV and ENVC methods. Monthly potential acid input (PAI) associated with dry species for each method is shown in Figure ES-1. The WBEA method also yielded higher PAI associated with dry species compared to the AENV and ENVC methods during winter and spring. The WBEA method gave similar PAI values associated with dry species during summer and fall. A simpler computational approach for aerodynamic and surface resistance terms in the WBEA method may partially explain differences observed during winter and spring. Further testing would be required to better understand whether this is the case.

3. Annual total PAI associated with dry species for 2003 was $0.14 \mathrm{~kg} \mathrm{H}^{+} / \mathrm{ha} / \mathrm{yr}$ (AENV method), $0.15 \mathrm{~kg} \mathrm{H}^{+} / \mathrm{ha} / \mathrm{yr}$ (ENVC method), and $0.20 \mathrm{~kg} \mathrm{H}^{+} / \mathrm{ha} / \mathrm{yr}$ (WBEA method). The higher annual rate observed for the WBEA method relative to other methods is consistent with higher monthly deposition rates for individual species. While the AENV and ENVC methods yielded comparable monthly PAI values associated with dry species, it is observed that ENVC input 
parameters have more boundary conditions (i.e. cut-off points and lower/upper limits) associated with their use compared to AENV input parameters.
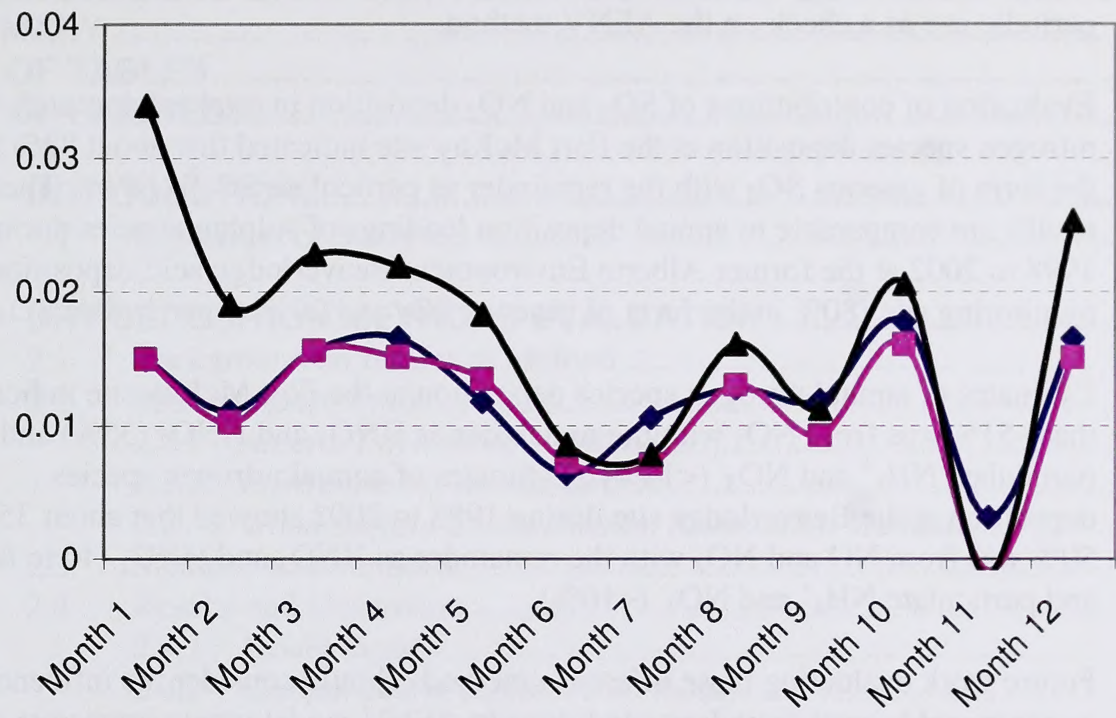

$\multimap$ ENVC $\rightarrow$ AENV $\leftarrow$ WBEA

Figure ES-1. Monthly potential acid input (PAI) values associated with dry species for the period January to December 2003 at WBEA Fort McKay air monitoring station AMS \#1 (expressed in units of $\mathrm{kg} \mathrm{H}+/ \mathrm{ha} / \mathrm{month}$ ).

$(\mathrm{ENVC}=$ Environment Canada method; $\mathrm{AENV}=$ Alberta Environment method; WBEA $=$ Wood Buffalo Environmental Association method)

4. The ENVC method is more complicated given that it has the greatest number of input parameter requirements. A number of additional assumptions for some of the input parameters are also required before modeling can be performed. The AENV method provided comparative results to the ENVC method. The AENV method is less complicated compared to the ENVC method, and it requires less input data and computing time. The WBEA method is simple and straightforward to use. However, this method yielded higher monthly deposition rates for most species modeled compared to the other methods using the 2003 dataset.

5. The dataset used to evaluate the methods was short - one year - and month to month variation or lack of variation in species deposition rates observed using each method does not necessarily provide an indication of what may happen in other years. Although only a one-year dataset was available for evaluation, 
results support that the AENV method offers a practical choice for routine computation of sulphur and nitrogen species dry deposition in Alberta. Further testing using different datasets elsewhere in Alberta is recommended to support this. If the ENVC method can be shown to provide comparable results to the AENV method using different datasets, it would offer a logical choice for periodic use as a check on the AENV method.

6. Evaluation of contributions of $\mathrm{SO}_{2}$ and $\mathrm{NO}_{2}$ deposition in total sulphur and nitrogen species deposition at the Fort McKay site indicated that about $82 \%$ is in the form of gaseous $\mathrm{SO}_{2}$ with the remainder as particulate $\mathrm{SO}_{4}{ }^{2-}(18 \%)$. These results are comparable to annual deposition loadings of sulphur species during 1998 to 2002 at the former Alberta Environment Beaverlodge acid deposition monitoring site ( $80 \%$ in the form of gaseous $\mathrm{SO}_{2}$ and $20 \%$ as particulate $\mathrm{SO}_{4}{ }^{2-}$ ).

Estimates of annual nitrogen species deposition at the Fort McKay site indicated that $\sim 51 \%$ was from $\mathrm{NO}_{2}$ with the remainder as $\mathrm{HNO}_{3}$ and $\mathrm{HNO}_{2}(35 \%)$ and particulate $\mathrm{NH}_{4}{ }^{+}$and $\mathrm{NO}_{3}{ }^{-}(<14 \%)$. Estimates of annual nitrogen species deposition at the Beaverlodge site during 1998 to 2002 showed that about 35 to $50 \%$ was from $\mathrm{NO}$ and $\mathrm{NO}_{2}$ with the remainder as $\mathrm{HNO}_{3}$ and $\mathrm{HNO}_{2}$ (40 to $60 \%$ ) and particulate $\mathrm{NH}_{4}{ }^{+}$and $\mathrm{NO}_{3}{ }^{-}(<10 \%)$.

7. Future work evaluating these inference methods should consider the influence of assigning additional boundary conditions to AENV model input parameters on variability associated with model outputs. Specifically, assigning boundary conditions to AENV input parameters consistent with default ENVC model assumptions should be investigated to better understand whether these changes have the ability to improve AENV model performance relative to the ENVC model. 


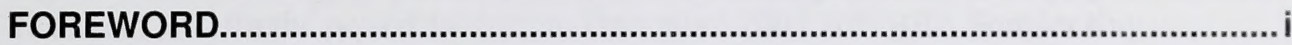

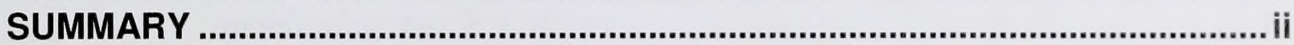

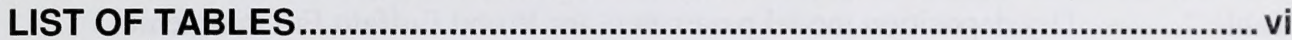

LIST OF FIGURES ......................................................................................... vii

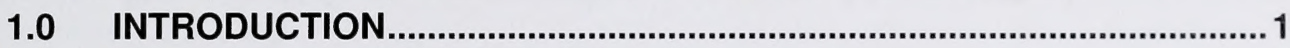

$1.1 \quad$ Objectives of Study …………………………......................................

2.0 DRY DEPOSITION METHODS EVALUATION ........................................

$2.1 \quad$ Background on Inference Method …………….......................................

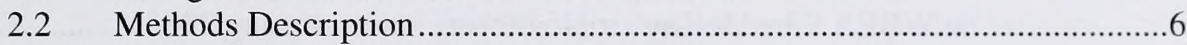

2.2.1 Alberta Environment Method..................................................

2.2.2 Environment Canada Method ......................................................

2.2.3 Wood Buffalo Environmental Association Method ............................

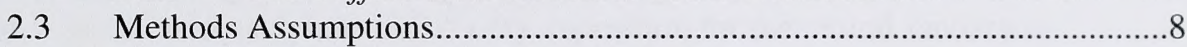

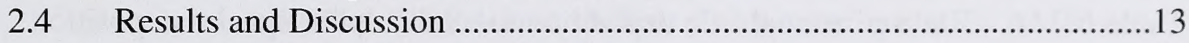

2.4.1 Model Results.......................................................................13

2.4.2 Comparison of Inference Methods...............................................22

2.4.3 Relationships of Dry Deposition for Sulphur and Nitrogen Species 24

2.4.3.1 Ratio .24

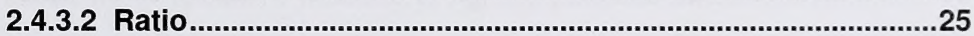

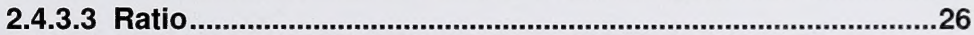

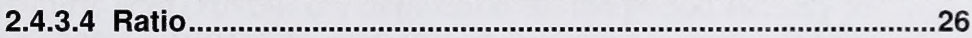

3.0 FINDINGS AND RECOMMENDATIONS ............................................27

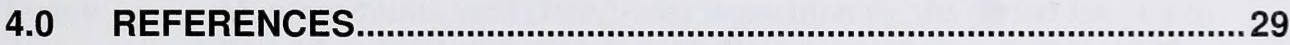

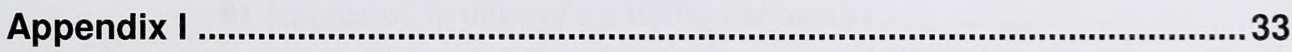

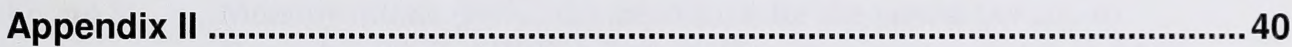

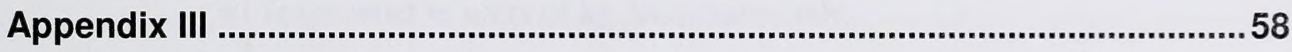




\section{LIST OF TABLES}

Table 1. Species commonly measured for dry deposition using the inference method.

Table 2. Dry deposition model parameters for Wood Buffalo Environmental Association Fort McKay air monitoring station - AMS \#1 - for the period 1 January 2003 to 31 December 2003. .8

Table 3. Relative comparison of selective features of three inference methods for estimating dry deposition.

Table 4 Ratio of annual $\mathrm{SO}_{2}$ deposition to total sulphur species deposition at WBEA Fort McKay air monitoring station during 2003.

Table 5 Ratio of annual $\mathrm{NO}_{2}$ deposition to total nitrogen species deposition at WBEA Fort McKay air monitoring station during 2003.

Table 6. Ratio of annual $\mathrm{SO}_{2}$ deposition to total sulphur species deposition at Beaverlodge, Alberta (after WBK, 2008).

Table 7. Ratio of annual $\mathrm{NO}_{\mathrm{x}}$ deposition to total nitrogen species deposition at Beaverlodge, Alberta (after WBK, 2008). 


\section{LIST OF FIGURES}

Figure ES-1 Monthly potential acid input (PAI) values associated with dry species for the period January to December 2003 at WBEA Fort McKay air monitoring station AMS \#1.

Figure 1. Relative locations where dry deposition resistance factors $R_{a}, R_{b}$, and $\mathrm{R}_{\mathrm{c}}$ apply

Figure 2. Location of acid deposition monitoring site (Fort McKay, AMS \#1) among oil sand lease holders in Wood Buffalo Environmental Association zone (after COST, 2006).

Figure 3. Monthly sulphur dioxide $\left(\mathrm{SO}_{2}\right)$ dry deposition for the period January to December 2003 at WBEA Fort McKay air monitoring station AMS \#1 (expressed in units of $\mathrm{kg} \mathrm{SO}_{2} / \mathrm{ha} / \mathrm{month}$ ).

Figure 4. Monthly sulphate $\left(\mathrm{SO}_{4}{ }^{2-}\right)$ dry deposition for the period January to December 2003 at WBEA Fort McKay air monitoring station AMS \#1 (expressed in units of $\mathrm{kg} \mathrm{SO}_{4}{ }^{2-} / \mathrm{ha} / \mathrm{month}$ ).

Figure 5. Monthly nitrogen dioxide $\left(\mathrm{NO}_{2}\right)$ dry deposition for the period January to December 2003 at WBEA Fort McKay air monitoring station AMS \#1 (expressed in units of $\mathrm{kg} \mathrm{NO}_{2} / \mathrm{ha} / \mathrm{month}$ ).

Figure 6. Monthly nitric acid $\left(\mathrm{HNO}_{3}\right)$ dry deposition for the period January to December 2003 at WBEA Fort McKay air monitoring station AMS \#1 (expressed in units of $\mathrm{kg} \mathrm{HNO}_{3} / \mathrm{ha} / \mathrm{month}$ ).

Figure 7. Monthly nitrous acid $\left(\mathrm{HNO}_{2}\right)$ dry deposition for the period January to December 2003 at WBEA Fort McKay air monitoring station AMS \#1 (expressed in units of $\mathrm{kg} \mathrm{HNO}_{2} / \mathrm{ha} /$ month).

Figure 8. Monthly nitrate $\left(\mathrm{NO}_{3}{ }^{-}\right)$dry deposition for the period January to December 2003 at WBEA Fort McKay air monitoring station AMS \#1 (expressed in units of $\mathrm{kg} \mathrm{NO}_{3}{ }^{-} / \mathrm{ha} /$ month).

Figure 9. Monthly ammonium $\left(\mathrm{NH}_{4}{ }^{+}\right)$dry deposition for the period January to December 2003 at WBEA Fort McKay air monitoring station AMS \#1 (expressed in units of $\mathrm{kg} \mathrm{NH}_{4}{ }^{+} / \mathrm{ha} /$ month).

Figure 10. Monthly potential acid input (PAI) values associated with dry species for the period January to December 2003 at WBEA Fort McKay air monitoring station AMS \#1 (expressed in units of $\mathrm{kg} \mathrm{H}^{+} / \mathrm{ha} / \mathrm{month}$ ). 


\section{$1.0 \quad$ INTRODUCTION}

Acid deposition occurs when acidifying pollutants emitted from anthropogenic and other processes undergo complex chemical reactions in the atmosphere and fall to the earth as wet deposition (rain, snow, cloud, fog) or dry deposition (dry particles, gas). The main chemical precursors leading to acidic pollutants are sulphur dioxide $\left(\mathrm{SO}_{2}\right)$ and oxides of nitrogen $\left(\mathrm{NO}_{\mathrm{x}}\right)$. Reactions of these pollutants with water, oxygen, carbon dioxide, and sunlight in the atmosphere produce acidic pollutants, e.g. sulphuric acid $\left(\mathrm{H}_{2} \mathrm{SO}_{4}\right)$, nitric acid $\left(\mathrm{HNO}_{3}\right)$, and nitrous acid $\left(\mathrm{HNO}_{2}\right)$. These and other acidic pollutants can be transported long distances in the atmosphere from their sources and eventually be deposited in ecosystems over broad regional scales and in locations far from the emission sources.

Dry deposition refers to removal of aerosol pollutants through eddy diffusion and impaction, large particles through gravitational settling, and gaseous pollutants through direct transfer from air to water via gas exchange. Dry deposition involves acidic sulphur and nitrogen pollutants (gases or particles) from the atmosphere being retained by the earth's surface. At the same time, co-deposition of base cations (e.g. $\mathrm{Na}^{+}, \mathrm{Mg}^{2+}, \mathrm{Ca}^{2+}$ and $\mathrm{K}^{+}$) results in a reduction of the amount of deposited acidity.

Potential acid input (PAI) provides a method of representing total acidic deposition (Cheng et al., 2001). PAI includes both wet and dry deposition. PAI is calculated by subtracting neutralizing capacity (base cation deposition) from deposition of acidic substances (e.g. sulphur and nitrogen species). Cheng et al. (2001, 1997) provide a detailed description of the estimation of total PAI. The PAI method does not include processes that remove acidity from the earth's surface (leaching, runoff, etc.).

\subsection{Objectives of Study}

Currently there is no standard method for the field measurement and estimation of dry deposition of acidifying pollutants in Alberta. Alberta Environment is pursuing development of an inexpensive technique for measuring and using inference methods for estimating sulphur and nitrogen species dry deposition. WBK (2008) reviewed current approaches used for measuring and estimating dry deposition.

An overall objective of this current study was to continue evaluating inferential methods for estimating dry deposition after WBK (2008). The purpose was to further investigate inferential methods that can be used by government and industry in Alberta for improved acid deposition management. Three different inference methods used in Canada for estimating sulphur and nitrogen species dry deposition were evaluated. A specific objective was to compare contributions of gaseous $\mathrm{SO}_{2}, \mathrm{NO}_{2}, \mathrm{HNO}_{3}, \mathrm{HNO}_{2}$, and particulate forms of sulphur and nitrogen in total sulphur and nitrogen dry deposition and identify potential relationships of each method. Another specific objective was to 
identify and recommend a preferred inference method (or methods) that could be routinely used for estimating sulphur and nitrogen species dry deposition rates in Alberta. 


\subsection{DRY DEPOSITION METHODS EVALUATION}

The Wood Buffalo Environmental Association (WBEA) collected complete sulphur and nitrogen gaseous and particulate species and meteorological data at the Fort McKay air monitoring station - AMS \#1 - during 2003. These data were used to evaluate relationships of sulphur and nitrogen species deposition using three inference methods applied in Canada. These methods were developed by:

- Alberta Environment (Cheng et al., 2001).

- Environment Canada (Zhang et al., 2003a, 2003b, 2002a, 2002b, 2001a, and 2001b).

- WBEA Terrestrial Environmental Effects Monitoring (TEEM) Committee (EPCM, 2002, 2000).

A specific objective of the evaluation was to compare contributions of gaseous $\mathrm{SO}_{2}, \mathrm{NO}_{2}$, $\mathrm{HNO}_{3}, \mathrm{HNO}_{2}$, and particulate forms of sulphur $\left(\mathrm{SO}_{4}{ }^{2-}\right)$ and nitrogen $\left(\mathrm{NO}_{3}{ }^{-}\right.$and $\left.\mathrm{NH}_{4}{ }^{+}\right)$in total sulphur and nitrogen deposition and their potential relationships among each method. Another specific objective of the evaluation was to identify and recommend a preferred inference method (or methods) that could be routinely used for estimating sulphur and nitrogen species dry deposition in Alberta.

\subsection{Background on Inference Method}

Dry deposition is generally far more a local problem than wet deposition. Estimating dry deposition rates is more difficult. Dry deposition depends on many factors, including: meteorological conditions, characteristics of the pollutants being deposited (e.g. particle size), and characteristics of the surface on which deposition occurs (US EPA, 2001).

A common approach to indirectly estimate dry deposition rates is on the basis of routinely measured air concentrations and meteorological parameters. Continuous and/or integrated measurement techniques are used to record the concentrations of atmospheric pollutants and continuous measurement techniques are used to record meteorological parameters. These parameters are used to estimate dry deposition using the most common method - the inference method (Cheng et al., 2001; Brook et al, 1999a, 1999b; Clarke et al., 1997).

The inference method involves indirect estimation of dry deposition rates on the basis of routinely measured air concentrations and meteorological parameters. The method is based on an assumed steady-state relationship $F=V_{d} C$, where dry deposition flux or rate $(\mathrm{F})$ is a product of the dry deposition velocity $\left(\mathrm{V}_{\mathrm{d}}\right)$ and the concentration $(\mathrm{C})$ of an airborne pollutant. $V_{d}$ is estimated on the basis of resistance models and is defined as the inverse of the sum of multiple resistance factors (aerodynamic resistance $\left(\mathrm{R}_{\mathrm{a}}\right)$, boundarylayer resistance $\left(R_{b}\right)$, and surface resistance $\left(R_{c}\right)$ ) (Wesely and Hicks, 2000, 1977): 


$$
\mathrm{V}_{\mathrm{d}}=\frac{1}{\left(R_{a}+R_{b}+R_{c}\right)}
$$

Figure 1 illustrates the relative locations where dry deposition resistance factors $R_{a}, R_{b}$, and $R_{c}$ apply near a surface.

Aerodynamic Resistance $\left(\mathrm{R}_{\mathrm{a}}\right)$. A shallow sub-layer occurs next to the ground that is within the atmospheric constant flux layer. The depth of this layer is in terms of meters (m) and depends upon atmospheric turbulence and stability, and surface characteristics (Cheng et al., 2001). The atmospheric resistance term, $R_{a}$, is used to parameterize the rate of pollutant transfer within this sub-layer as a function of atmospheric turbulence and stability, and surface characteristics (Wesely and Hicks, 1977).

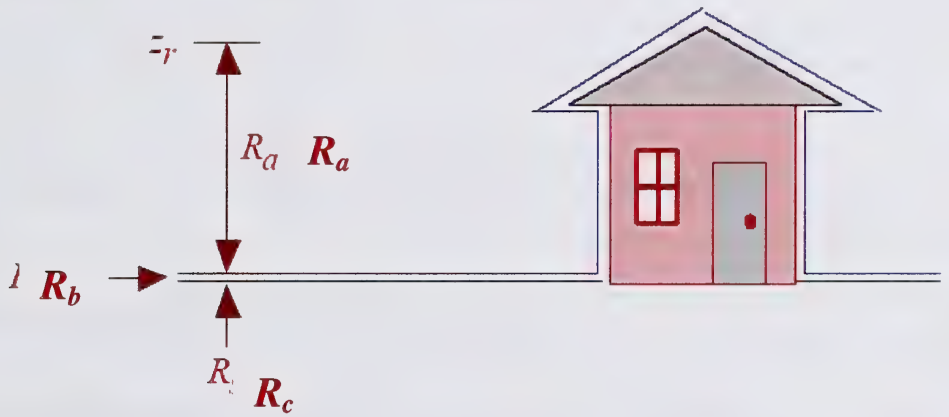

Figure 1. Relative locations where dry deposition resistance factors $\mathbf{R}_{a}, \mathbf{R}_{b}$, and $\mathbf{R}_{\mathrm{c}}$ apply.

Boundary-layer Resistance $\left(\mathrm{R}_{\mathrm{b}}\right)$. The boundary layer is a thin, non-turbulent layer that develops just above the surface. The depth of this layer is in terms of millimeters (mm). For rough surfaces, this layer is constantly changing and Hicks (1982) reported that is likely to be intermittently turbulent. The rate of pollutant transfer within this layer is determined by molecular diffusion for gases and Brownian diffusion and inertial impaction for particles. The boundary-layer resistance term, $\mathrm{R}_{\mathrm{b}}$, is usually parameterized in terms of the Schmidt number (viscosity of air divided by the diffusivity of the pollutant) and, for particles, the Stokes number (which is a function of the gravitation settling velocity, friction velocity, and the viscosity of air).

Surface Resistance $\left(\mathrm{R}_{\mathrm{c}}\right)$. Vegetation is a major sink for soluble or reactive gaseous pollutants. After passing through stomata of vegetation, soluble pollutants dissolve in moist mesophyll cells in the interior of leaves (Wesely and Hicks, 1977). Reactive pollutants, e.g. ozone, may also interact with the exterior (cuticle) of the leaves. Due to response of the stomata to external factors such as moisture stress, temperature, and solar 
radiation, resistance in the vegetation layer can exhibit significant diurnal and seasonal variability. The surface resistance term, $R_{c}$, is usually parameterized in terms of the three main pathways for uptake/reaction of a pollutant within the vegetation or surface (Wesely and Hicks, 1977):

- Transfer through stomatal pores and dissolution or reaction in the mesophyll cells.

- Reaction with or transfer through the leaf cuticle.

- Transfer into the ground/water surface.

Cheng et al. (2001) provide additional information on components that are measured and/or observed in estimating the surface resistance factor.

Atmospheric Pollutants. Atmospheric species commonly measured for dry deposition using the inference method are presented in Table 1. Wesely and Hicks (2000) report that $\mathrm{NO}$ dry deposition is usually negligible because of its low solubility and low oxidizing capacity. It is usually not considered for measurement. Cheng et al. (2001) recommend that gaseous ammonia $\left(\mathrm{NH}_{3}\right)$ not be considered when estimating dry deposition because sufficient understanding of its biochemistry has yet to be achieved.

Table 1. Species commonly measured for dry deposition using the inference method.

- Sulphur species (gaseous $\mathrm{SO}_{2}$ and $\mathrm{SO}_{4}{ }^{2-}$ in particulate matter).

- Nitrogen species (gaseous $\mathrm{NO}_{2}$, acidic gases $\mathrm{HNO}_{3}$ and $\mathrm{HNO}_{2}$, and particulate $\mathrm{NH}_{4}{ }^{+}$and $\mathrm{NO}_{3}^{-}$).

- Particulate base cations $\left(\mathrm{Na}^{+}, \mathrm{Mg}^{2+}, \mathrm{Ca}^{2+}\right.$ and $\mathrm{K}^{+}$). Co-deposition of these base cations results in a reduction of the amount of deposited acidity.

Particle-associated species derived from erosion of soil or plant material $\left(\mathrm{Na}^{+}, \mathrm{K}^{+}, \mathrm{Mg}^{2+}\right.$, and $\mathrm{Ca}^{2+}$ ) tend to reside on larger airborne particles (e.g. $>2 \mu \mathrm{m}$ ) (Lovett, 1994). The majority of airborne mass of $\mathrm{NH}_{4}{ }^{+}, \mathrm{SO}_{4}{ }^{2-}$, and $\mathrm{H}^{+}$reside on submicrometer aerosols. Thus collecting $\mathrm{PM}_{10}$ or larger-sized airborne particles (TSP) provide more efficient capture of particle-associated species derived from erosion of soil or plant material.

Concentrations of the eleven species are combined into Equation 2 to estimate potential dry acid input surface load $\left(\mathrm{PAI}_{\mathrm{dry}}\right)$ in kilogram hydrogen equivalents (Cheng et al., 2001):

$$
\begin{aligned}
\mathrm{PAI}_{\mathrm{dry}}= & \frac{\left[\mathrm{SO}_{2}\right]}{64}+\frac{\left[\mathrm{NO}_{2}\right]}{46}+\frac{\left[\mathrm{HNO}_{2}\right]}{47}+\frac{\left[\mathrm{HNO}_{3}\right]}{63}+2 \frac{\left[\mathrm{SO}_{4}^{2-}\right]}{96}+\frac{\left[\mathrm{NO}_{3}^{-}\right]}{62}+\frac{\left[\mathrm{NH}_{4}^{+}\right]}{18} \\
& -\left(\frac{\left[\mathrm{K}^{+}\right]}{39}+\frac{\left[\mathrm{Na}^{+}\right]}{23}+2 \frac{\left[\mathrm{Ca}^{2+}\right]}{40}+2 \frac{\left[\mathrm{Mg}^{2+}\right]}{24}\right) \quad[\mathrm{kg} \mathrm{H} / \mathrm{ha} / \mathrm{yr}]
\end{aligned}
$$


Meteorological Parameters. Continuous measurement of numerous meteorological variables is necessary to allow estimation of dry deposition of gaseous and particulatebound species to specific surfaces using the inference method. Meteorological variables ultimately required are one-hour or 15-minute standard deviation of wind direction, wind speed, solar radiation, and air temperature at standard height $(10 \mathrm{~m})$ and near the surface (2 m) (EPCM, 2000). These temperatures are used to establish atmospheric stability. The presence or absence of a wet surface also affects dry deposition. Consequently, surface wetness sensing and relative humidity measurements are required. In summary, continuous measurement of the following meteorological variables is required for estimating gaseous and particulate-bound species dry deposition using the inference method:

- Wind speed and wind speed standard deviation

- Wind direction and wind direction standard deviation

- Solar radiation

- Relative humidity

- Surface wetness

- Air temperature at standard height $(10 \mathrm{~m})$

- Difference in air temperature at standard height and surface (taken as $2 \mathrm{~m}$ above ground).

\subsection{Methods Description}

\subsubsection{Alberta Environment Method}

Alberta Environment uses an inferential method to estimate aerodynamic $\left(\mathrm{R}_{\mathrm{a}}\right)$, boundarylayer $\left(R_{b}\right)$, and surface (canopy) resistances $\left(R_{c}\right)$ (Cheng et al., 2001). The method parameterizes dry deposition in terms of a deposition velocity $\left(\mathrm{V}_{\mathrm{d}}\right)$ that is inferred from measured meteorological parameters and surface characteristics (Equation 1).

Hourly deposition fluxes for each species are calculated as a product of the hourly $\mathrm{V}_{\mathrm{d}}$ and the corresponding hourly concentration (C). Total daily dry deposition is the sum of deposition over twenty-four hours. In turn, monthly, seasonal, and annual totals are derived by summing all daily totals for a month, season or year, respectively. WBK (2008) used this method to estimate annual sulphur and nitrogen species deposition using datasets at the Alberta Environment acid deposition monitoring site at Beaverlodge, Alberta for the 1998 to 2002 period. Parameters and equations used in the Alberta Environment method are presented in Appendix I.

\subsubsection{Environment Canada Method}

Environment Canada uses another variation of the inferential method to estimate dry deposition velocities of acidic species at sites in their national dry deposition monitoring 
network (Zhang et al., 2003a, 2003b, 2002a, 2002b, 2001a, and 2001b). Their approach is known as A Unified Regional Air Quality Modeling System (AURAMS) (Zhang et al., 2002a). The network is referred to as the Canadian Air and Precipitation Monitoring Network (CAPMoN) (http://www.msc-smc.ec.gc.ca/capmon/index_e.cfm).

A Big Leaf model is used for gaseous dry deposition in AURAMS (Zhang et al., 2002a). A size-segregated particle dry deposition module originally developed by the Meteorological Service of Canada is used for particle dry deposition in AURAMS (Zhang et al., 2001).

AURAMS was recently revised to include non-stomatal resistance parameterizations (Zhang et al., 2003b). The Big Leaf model developed by Zhang et al. (2002a) was developed for calculating dry deposition velocities for more than 40 gaseous species for AURAMS, but it only included seasonally-adjusted values for non-stomatal resistance. The revised model incorporates non-stomatal resistance parameterizations (Zhang et al., 2003a; Zhang et al., 2002b). Other improvements included more practical treatment of cuticle and ground resistance in winter and handling of seasonally-dependent input parameters.

Similar to the Alberta Environment method, AURAMS uses 1-hour average values of meteorological observations for estimating resistance terms. For a typical 31-day month, $31 \times 24=744$ different hourly meteorological observations are used to compute a similar number of hourly average deposition velocities and deposition loadings for each acidic species. A monthly deposition load is computed by summing individual hourly average loadings (deposition velocity $\mathrm{x}$ concentration for each hour). Parameters and equations used in the Environment Canada approach are presented in Appendix II.

\subsubsection{Wood Buffalo Environmental Association Method}

EPCM $(2002,2000)$ developed a method for estimating $\mathrm{SO}_{2}$ and $\mathrm{NO}_{2}$ dry deposition for the Wood Buffalo Environmental Association Terrestrial Environmental Effects Monitoring (TEEM) Committee. Aerodynamic $\left(\mathrm{R}_{\mathrm{a}}\right)$ and boundary layer $\left(\mathrm{R}_{\mathrm{b}}\right)$ resistances are determined using simplified empirical relationships. Surface (canopy) resistance $\left(\mathbf{R}_{\mathrm{c}}\right)$ is determined using an approach very similar to that used by Alberta Environment. These relationships are described in Appendix III.

The method uses fifteen-minute average values of meteorological observations to estimate resistance terms. For a typical 31-day month, 31 x 24 x $4=2,976$ different 15 minute meteorological observations are used to compute a similar number of 15-minute average deposition velocities and deposition loadings for each acidic parameter. A monthly deposition load is computed by summing individual 15-minute average loadings for that month. 


\subsection{Methods Assumptions}

WBEA data gaseous and particulate species and meteorological data at the Fort McKay air monitoring station are shown in Table 2. The location of AMS \#1 relative to oil sand lease hold areas in WBEA zone is shown in Figure 2. Hourly data for parameters listed in Table 2 were received in electronic form from WBEA. These data were compiled, processed, and evaluated using the three inferential methods mentioned previously.

A number of assumptions were required beyond what each method offered as default assumptions or boundary conditions in order to enable modeling to be performed. These assumptions are listed below. The intent for presenting these assumptions is to allow others to conduct similar model evaluations using the same (or other) inferential methods and dataset.

1. Default characteristics (specific location and land use category) of the Fort McKay air monitoring station (AMS \#1):

\begin{tabular}{lll} 
Latitude & 57.2 & South Negative \\
Longitude & -111.6 & West Negative \\
Time zone & -5 & West Negative \\
Reference height $(z)$ & $10 \mathrm{~m}$ & \\
Land Use Category (LUC) & \multicolumn{2}{l}{ Coniferous Forest }
\end{tabular}

Table 2. Dry deposition model parameters for Wood Buffalo Environmental Association Fort McKay air monitoring station - AMS \#1 - for the period 1 January 2003 to 31 December 2003.

\begin{tabular}{ll} 
Components & Parameters \\
\hline Combustion gases & Continuous (hourly) $\mathrm{SO}_{2}$ and $\mathrm{NO}_{2}$ \\
Acid gases & 24-hour integrated annular denuder sample every $6^{\text {th }}$ day for $\mathrm{HNO}_{3}, \mathrm{HNO}_{2}$, and \\
& $\mathrm{NH}_{3}$ \\
Particulate-associated & 24 -hour integrated $\mathrm{PM}_{2.5}$ and $\mathrm{PM}_{10}$ sample every $6^{\text {th }}$ day for $\mathrm{NH}^{4+}, \mathrm{SO}_{4}{ }^{2-}$, and \\
acidic species & $\mathrm{NO}_{3}^{-}$ \\
Particulate-associated & 24 -hour integrated $\mathrm{PM}_{2.5}$ and $\mathrm{PM}_{10}$ sample every $6^{\text {th }}$ day for $\mathrm{Na}^{+}, \mathrm{K}^{+}, \mathrm{Mg}^{2+}$, and \\
base cation species & $\mathrm{Ca}^{2+}$ \\
Meteorological & Wind speed and wind speed standard deviation \\
parameters & Wind direction and wind direction standard deviation \\
(recorded hourly) & $\begin{array}{l}\text { Solar radiation } \\
\text { Relative humidity } \\
\text { Surface wetness } \\
\text { Air temperature at standard height }(10 \mathrm{~m}) \\
\text { Difference in air temperature at standard height and surface (taken as } 2 \mathrm{~m} \text { above } \\
\text { ground) }\end{array}$ \\
\hline
\end{tabular}


2. Data preprocessing procedures:

a. Invalid or missing hourly data values for were replaced by the month's hourly median value for two or more successive invalid or missing hourly data points.

b. Invalid or missing hourly data values were replaced by an average of previous and succeeding hourly value for one invalid or missing hourly data point.

c. Intermittent hourly data (i.e. samples collected for 24 hours every $6^{\text {th }}$ day) were assumed to have the same value for whole 6-day sampling period.

d. Hourly $\mathrm{NO}_{2}$ and $\mathrm{SO}_{2}$ concentrations were converted from ppbv to $\mu \mathrm{g} / \mathrm{m}^{3}$ at standard conditions $\left(25^{\circ} \mathrm{C}\right.$ and $\left.101.325 \mathrm{kPa}\right)$.

3. Solar and earth system coordinates:

Solar zenith angle $(\theta)$ and solar radiation (SR) were used in the Environment Canada (WBEA) model and Wood Buffalo Environmental Association (WBEA) model. A Visual Basic program was developed to compute those parameters. The results of this program were confirmed with data obtained from the Astronomical Applications Department, US Naval Observatory (http://aa.usno.navy.mil/).

In general, if no solar radiation data were available, solar radiation (SR) was assumed equal to $1000 * \operatorname{cosine}$ of solar zenith angle (i.e. $1000 * \cos \theta$ ).

4. Alberta Environment model general assumptions:

Model's equations were adapted from Cheng et al. (2005) and are listed in Appendix I. These equations were programmed in MS EXCEL ${ }^{\circledR}$ using Visual Basic.

a. Surface resistance $\left(R_{c}\right)$ for all species and boundary-layer resistance $\left(R_{b}\right)$ for particles were weighted based on $54^{\circ} \mathrm{N}$ latitude for each season.

b. $\mathrm{HNO}_{3}$ was assumed to have the same $\mathrm{R}_{\mathrm{b}}$ as $\mathrm{SO}_{2}$.

c. $\mathrm{NH}_{4}{ }^{+}$was assumed to have the same $\mathrm{R}_{\mathrm{b}}$ as $\mathrm{SO}_{4}{ }^{2-}$.

d. $\mathrm{R}_{\mathrm{b}}$ for $\mathrm{NO}_{3}{ }^{-}, \mathrm{Na}^{+}, \mathrm{K}^{+}, \mathrm{Ca}^{2+}$, and $\mathrm{Mg}^{2+}$ assumed to be the same and half of the $\mathrm{R}_{\mathrm{b}}$ of $\mathrm{SO}_{4}^{2-}$.

e. $\quad \mathrm{R}_{\mathrm{c}}$ for $\mathrm{SO}_{2}$ and $\mathrm{NO}_{2}$ were based on default values listed in Table 4.4 and 4.5 of Cheng et al. (2001).

f. $\mathrm{R}_{\mathrm{c}}$ for $\mathrm{HNO}_{3}$ and $\mathrm{HNO}_{2}$ was assumed to be equal to $0.1 \mathrm{~s} / \mathrm{cm}$ for all surfaces and all seasons.

g. $\quad R_{c}$ for all particulate species assumed equal to zero. 


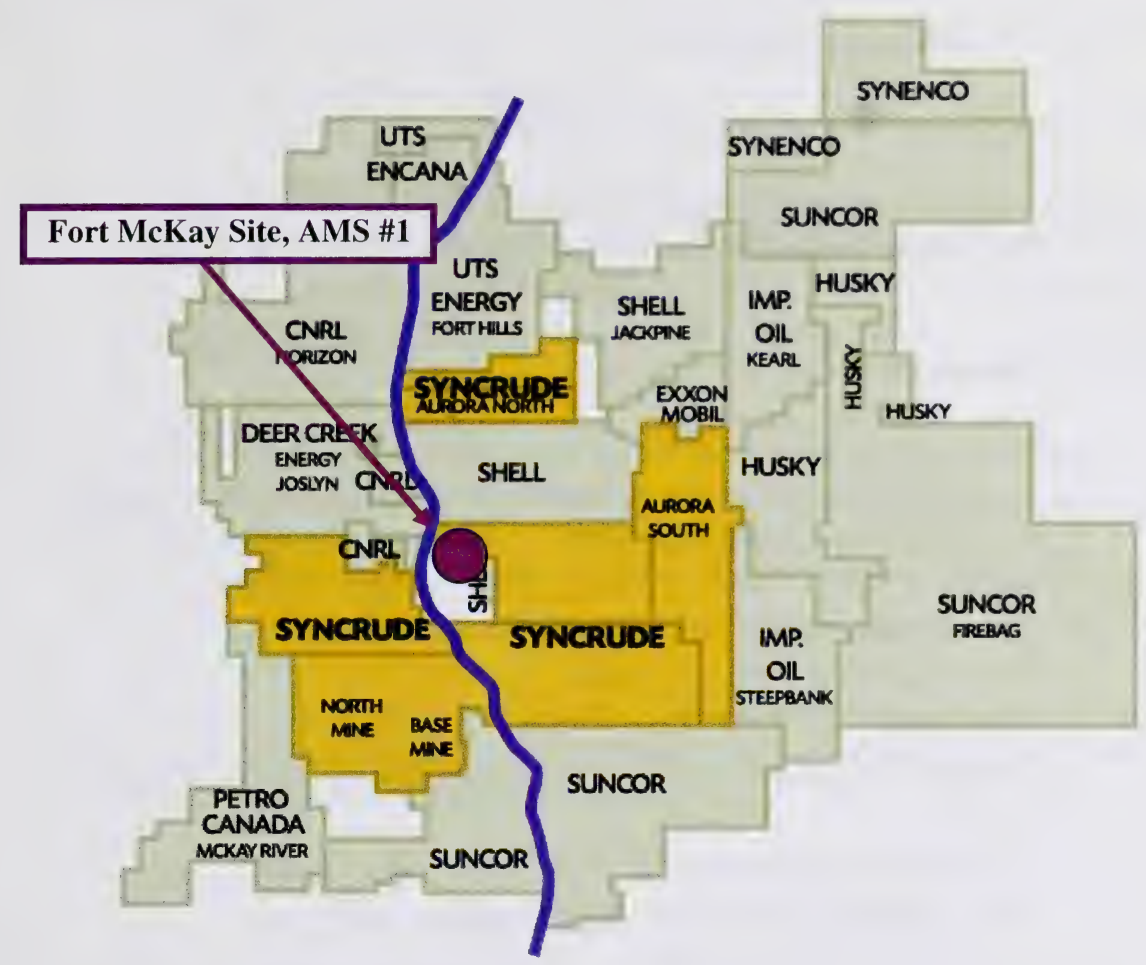

Figure 2. Location of acid deposition monitoring site (Fort McKay, AMS \#1) among oil sand lease holders in Wood Buffalo Environmental Association zone (after COST, 2006).

h. Surface roughness length $\left(\mathrm{z}_{0}\right)$ was computed from the wind speed at reference height $(u)$ and standard deviation of the wind direction $\left(\sigma_{\theta}\right)$ when wind speed $>6 \mathrm{~m} / \mathrm{s}$.

i. No available conditions were available for $\mathrm{z}_{0}$ for the month of February, 2003. Therefore, the average $\mathrm{z}_{0}$ of January and March was used to represent conditions for this month.

j. Boundary conditions (cut-off points used) included:

i. If horizontal wind speed at reference height $(u)<0.36 \mathrm{~km} / \mathrm{h}$, then $u=0$ and deposition velocity $\left(V_{d}\right)=0$.

ii. If temperature difference $\left(T_{d}\right)=0$, then $V_{d}=0$.

iii. Weighted-average $R_{c}$ was set constant for each season.

k. Surface wetness conditions:

i. If precipitation ( $\mathrm{Prec})>0.1 \mathrm{~mm} / \mathrm{hour}$, it is raining and $V_{d}=V_{d}$ (wet).

ii. If relative humidity (RH) $>87.4 \%$, it is raining and $V_{d}=V_{d}$ (wet). 
iii. $\quad V_{d}=$ Wetness-weighted $V_{d}$.

5. Environment Canada model general assumptions:

An electronic file originally programmed using FORTRAN was reprogrammed in MS EXCEL ${ }^{\circledR}$ using Visual Basic. Details of model equations are listed in Appendix II.

Gaseous model component assumptions:

a. Daily precipitation amounts for the Environment Canada Fort McMurray Airport meteorological station were obtained from Environment Canada (Edmonton, AB). The squared hourly cloud fraction was used as an hourly weight to convert daily precipitation to hourly precipitation.

b. Boundary conditions (cut-off points used) included:

i. If $u<3.6 \mathrm{~km} / \mathrm{h}$, set $\underline{\mathrm{u}}=3.6 \mathrm{~km} / \mathrm{h}$.

ii. If $T_{d}<1 \mathrm{E}^{-10}$, set $T_{d}=1 \mathrm{E}^{-10}$.

iii. If Bulk Richardson number $(R i)>0$ and solar radiation (SR) $>0 \mathrm{w} / \mathrm{m}^{2}$, set $R i=1 \mathrm{E}^{-15}$.

iv. If Monin-Obukhov Length ( $\mathrm{L})>5$, set $\mathrm{L}=5$.

v. If aerodynamic resistance $\left(R_{a}\right)<5$, set $R_{a}=5$.

vi. If $R_{a}>1000$, set $R_{a}=1000$.

vii. If $R_{c}<10$, set $R_{c}=10$.

c. Surface wetness conditions:

i. If precipitation (Prec) $>0.1 \mathrm{~mm} / \mathrm{h}$, it is raining.

ii. If $\mathrm{RH}>$ dew point, set $\mathrm{RH}$ to dew point.

iii. If rainy or dew-point condition exist, fraction of stomatal blocking under wet conditions $\left(W_{s t}\right)=\left(S_{\text {rad }}-200\right) / 800$.

iv. If $W_{s t}<0.5$, set $W_{s t}=0.5$.

v. $W_{s t}$-weighted $\mathrm{R}_{\mathrm{c}}$ used to calculate $V_{d}$.

Particulate model component assumptions:

a. Particulate matter size was assumed to follow lognormal distribution from $0.001 \mathrm{~nm}$ to $10 \mu \mathrm{m}$.

b. $\mathrm{SO}_{4}{ }^{2-}$ in particulate form was assumed to follow lognormal distribution with $\mathrm{MMD}=0.35 \mu \mathrm{m}$ and $\mathrm{GSD}=2.0$.

c. $\mathrm{NH}_{4}{ }^{+}$was assumed to have same $V_{d}$ as $\mathrm{SO}_{4}{ }^{2-}$.

d. $\mathrm{Na}^{+}$in particulate form was assumed to follow lognormal distribution with $\mathrm{MMD}=5.12 \mu \mathrm{m}$ and $\mathrm{GSD}=2.64$.

e. $\mathrm{NO}_{3}{ }^{-}, \mathrm{K}^{+}, \mathrm{Ca}^{2+}$, and $\mathrm{Mg}^{2+}$ were assumed to have same $V_{d}$ as $\mathrm{Na}^{+}$.

f. Boundary conditions (cut-off points used) included: 
i. If $u<3.6 \mathrm{~km} / \mathrm{h}$, set $\mathrm{U}=3.6 \mathrm{~km} / \mathrm{h}$.

ii. If $T_{d}<1 \mathrm{E}^{-10}$, set $T_{d}=1 \mathrm{E}^{-10}$.

iii. If $R i>0$ and $\mathrm{SR}>0 \mathrm{w} / \mathrm{m}^{2}$, set $R i=1 \mathrm{E}^{-15}$.

iv. If Monin-Obukhov Length ( $\mathrm{L})>5$, set $\mathrm{L}=5$.

v. If aerodynamic resistance $\left(\mathrm{R}_{\mathrm{a}}\right)<5$, set $\mathrm{R}_{\mathrm{a}}=5$. $\mathrm{p}$

vi. If $R_{a}>999.9$, set $R_{a}=999.9$.

g. No criteria are used for surface wetness conditions.

6. Wood Buffalo Environmental Association (WBEA) model:

Equations for this method were obtained from WBEA Excel files and related documentation (EPCM 2002, 2000) received from the Wood Buffalo Environmental Association. These equations are listed in Appendix III. These equations were programmed in MS EXCEL ${ }^{\circledR}$ using Visual Basic.

This model was developed to process input parameters as 15-minute averages. However model runs used 1-hour average values for input parameters as 15minute average values were unavailable.

a. Atmospheric conditions:

a. stable for night time.

b. unstable for day time.

b. $\mathrm{HNO}_{3}$ assumed to have same $\mathrm{R}_{\mathrm{b}}$ as $\mathrm{SO}_{2}$.

c. $\mathrm{NH}_{4}{ }^{+}$assumed to have same $\mathrm{R}_{\mathrm{b}}$ as $\mathrm{SO}_{4}{ }^{2-}$.

d. $\mathrm{R}_{\mathrm{b}}$ for $\mathrm{NO}_{3}{ }^{-}, \mathrm{Na}^{+}, \mathrm{K}^{+}, \mathrm{Ca}^{2+}$, and $\mathrm{Mg}^{2+}$ assumed to be the same and half of $\mathrm{R}_{\mathrm{b}}$ of $\mathrm{SO}_{4}{ }^{2-}$

e. $\quad \mathrm{R}_{\mathrm{c}}$ for $\mathrm{SO}_{2}$ and $\mathrm{NO}_{2}$ were based on default values listed in Table 4.4 and 4.5 of Cheng et al. (2001).

f. $\quad \mathrm{R}_{\mathrm{c}}$ for $\mathrm{HNO}_{3}$ and $\mathrm{HNO}_{2}$ assumed equal to $0.1 \mathrm{~s} / \mathrm{cm}$ for all surfaces and all seasons.

g. $\quad R_{c}$ for all particles assumed equal to zero.

h. Boundary conditions (cut-off points used) included:

a. If $u<0.36 \mathrm{~km} / \mathrm{h}$ : set $u=0$

b. $\mathrm{R}_{\mathrm{a}} \leq 1000$

c. $R_{b} \leq 1000$

i. Surface wetness conditions:

a. If precipitation (Prec) $>0.1 \mathrm{~mm} /$ hour, it is raining and $V_{d}=V_{d}$ (wet).

b. If $\mathrm{RH}>87.4 \%$, it is raining and $V_{d}=V_{d}$ (wet). 


\subsection{Results and Discussion}

\subsubsection{Model Results}

Individual Species Deposition - Estimated monthly dry deposition rates for a number of sulphur and nitrogen species at the Fort McKay site are presented for each inference method in Figures 3 to 9. Monthly dry deposition rates for sulphur species $-\mathrm{SO}_{2}$ and $\mathrm{SO}_{4}{ }^{2-}$ - are presented in Figures 3 and 4, respectively. Monthly dry deposition rates for nitrogen species $-\mathrm{NO}_{2}, \mathrm{HNO}_{3}, \mathrm{HNO}_{2}, \mathrm{NO}_{3}{ }^{-}$, and $\mathrm{NH}_{4}{ }^{+}$- are presented in Figures 5 to 9 , respectively. All deposition rates are expressed in "kg species/ha/month."

As a general observation, all three inference methods show a similar ability to represent changes (variation) in dry deposition rates from month to month. For example, Figure 3 illustrates monthly $\mathrm{SO}_{2}$ dry deposition rates as $\mathrm{kg} \mathrm{SO}_{2} / \mathrm{ha} / \mathrm{month}$. The $4^{\text {th }}, 7^{\text {th }}$, and $8^{\text {th }}$ months of the year clearly show higher deposition rates for each method relative to other months. In this particular instance the Environment Canada (ENVC) method yields higher monthly $\mathrm{SO}_{2}$ deposition rates relative to the other two methods.

Another general observation is made is that the Wood Buffalo Environmental Association (WBEA) method yields higher monthly deposition rates for most species modeled using the 2003 dataset. This includes $\mathrm{SO}_{4}{ }^{2-}$ (Figure 4), $\mathrm{NO}_{2}$ (Figure 5), $\mathrm{HNO}_{3}$ (Figure 6), $\mathrm{HNO}_{2}$ (Figure 7), and $\mathrm{NH}_{4}{ }^{+}$(Figure 9).

Potential Acid Input - Estimated monthly total potential acid input (PAI) associated with dry species at the Fort McKay site are presented for each inference method in Figure 10. These rates are expressed in units of $\mathrm{kg} \mathrm{H}^{+} / \mathrm{ha} / \mathrm{yr}$ and they were computed taking into account all sulphur, nitrogen, and base cation species as shown in Equation 2. Similar to findings reported above, Figure 10 shows that the WBEA method gives higher PAI rates associated with dry species during the winter and spring months using the 2003 dataset.

The WBEA method gives similar rates as the ENVC and AENV methods during other seasons (i.e. summer and fall). It is initially suspected that a simpler computational approach for the aerodynamic $\left(\mathrm{R}_{\mathrm{a}}\right.$ ) and surface $\left(\mathrm{R}_{\mathrm{b}}\right)$ resistance terms in the WBEA method (Appendix III) partially accounts for this departure during winter and spring months. However, further testing would be necessary to better understand whether this is the case.

A general observation is made regarding the performance of each method and their ability to represent change (variation) in monthly total PAI rates associated with dry species shown in Figure 10. The ENVC and AENV method yield comparable monthly total PAI rates associated with dry species, except for the $11^{\text {th }}$ month (November) where the AENV yields a net negative rate. The exact reasons for this departure in the $11^{\text {th }}$ month are unknown, however it may be due to greater equivalent total base cation species deposition flux relative to equivalent total sulphur and nitrogen species flux during the month. 


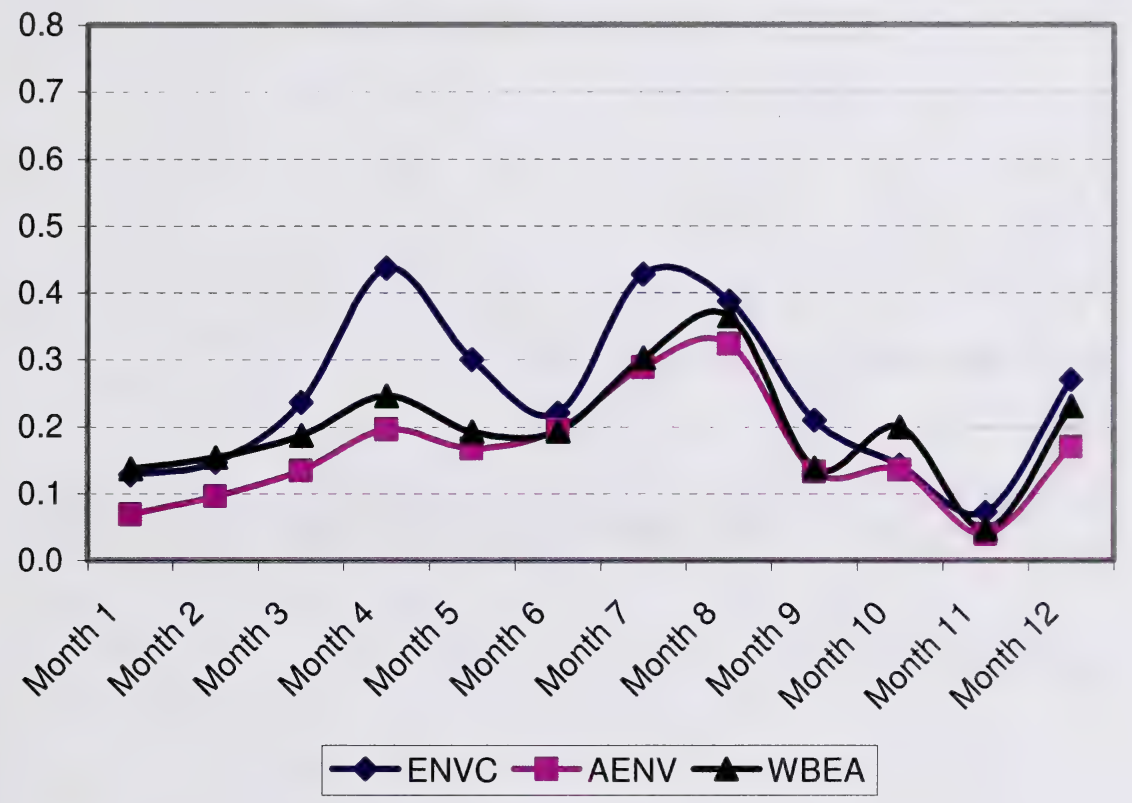

Figure 3. Monthly sulphur dioxide $\left(\mathrm{SO}_{2}\right)$ dry deposition for the period January to December 2003 at WBEA Fort McKay air monitoring station AMS \#1 (expressed in units of $\mathrm{kg} \mathrm{SO}_{2} / \mathrm{ha} /$ month).

$($ ENVC $=$ Environment Canada method; $\mathrm{AENV}=$ Alberta Environment method;

WBEA $=$ Wood Buffalo Environmental Association method) 


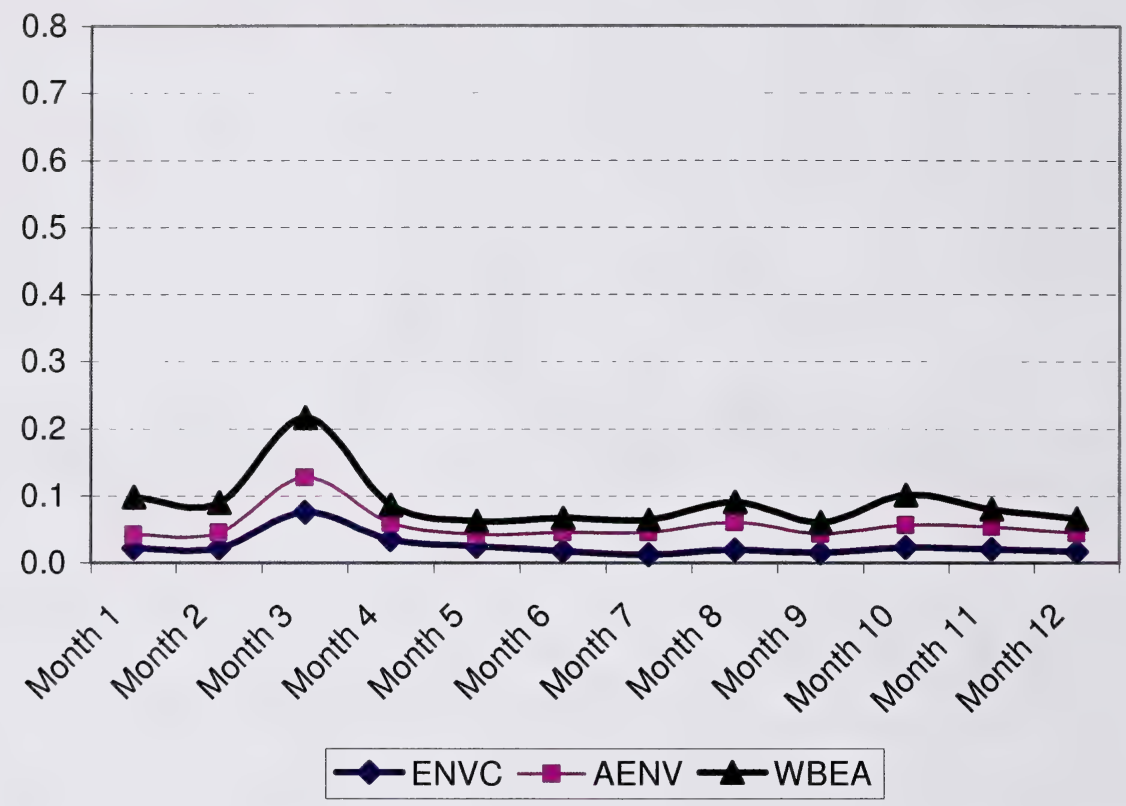

Figure 4. Monthly sulphate $\left(\mathrm{SO}_{4}{ }^{2-}\right)$ dry deposition for the period January to December 2003 at WBEA Fort McKay air monitoring station AMS \#1 (expressed in units of $\mathrm{kg} \mathrm{SO}_{4}{ }^{2-} / \mathrm{ha} / \mathrm{month}$ ).

$($ ENVC $=$ Environment Canada method; AENV $=$ Alberta Environment method; WBEA = Wood Buffalo Environmental Association method) 


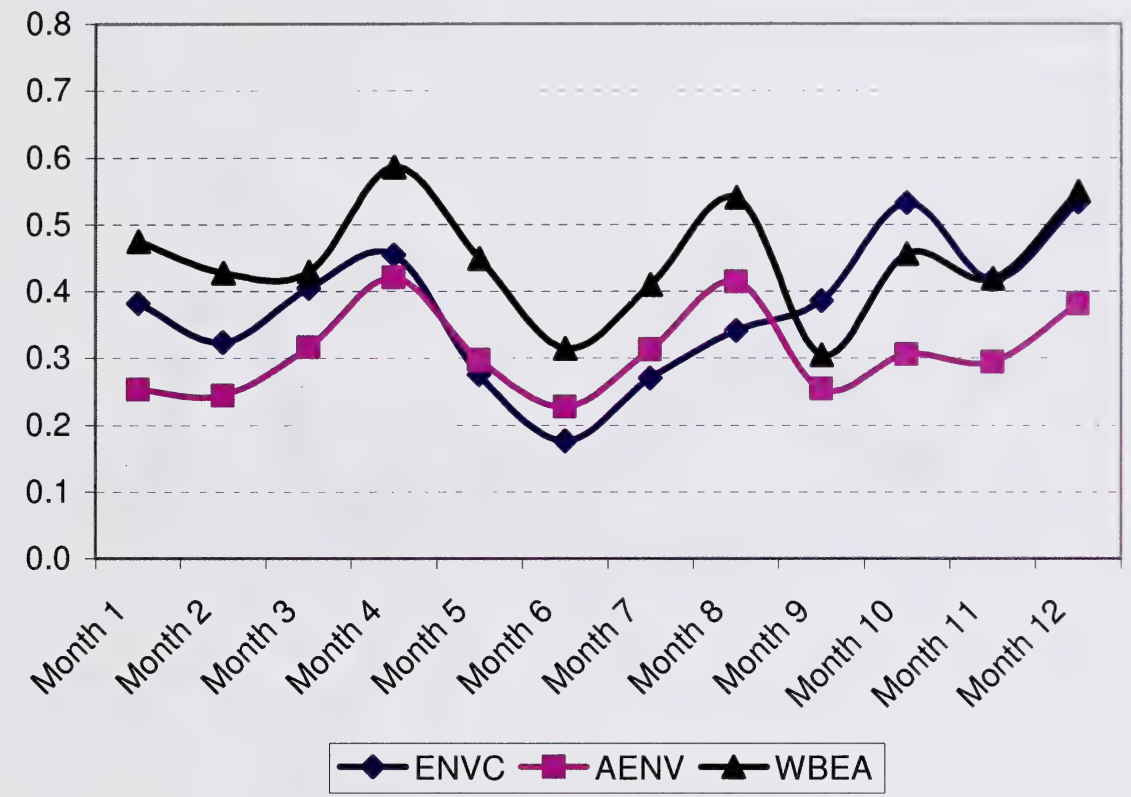

Figure 5. Monthly nitrogen dioxide $\left(\mathrm{NO}_{2}\right)$ dry deposition for the period January to December 2003 at WBEA Fort McKay air monitoring station AMS \#1 (expressed in units of $\mathrm{kg} \mathrm{NO}_{2} / \mathrm{ha} / \mathrm{month}$ ).

$(\mathrm{ENVC}=$ Environment Canada method; $\mathrm{AENV}=$ Alberta Environment method; WBEA = Wood Buffalo Environmental Association method) 


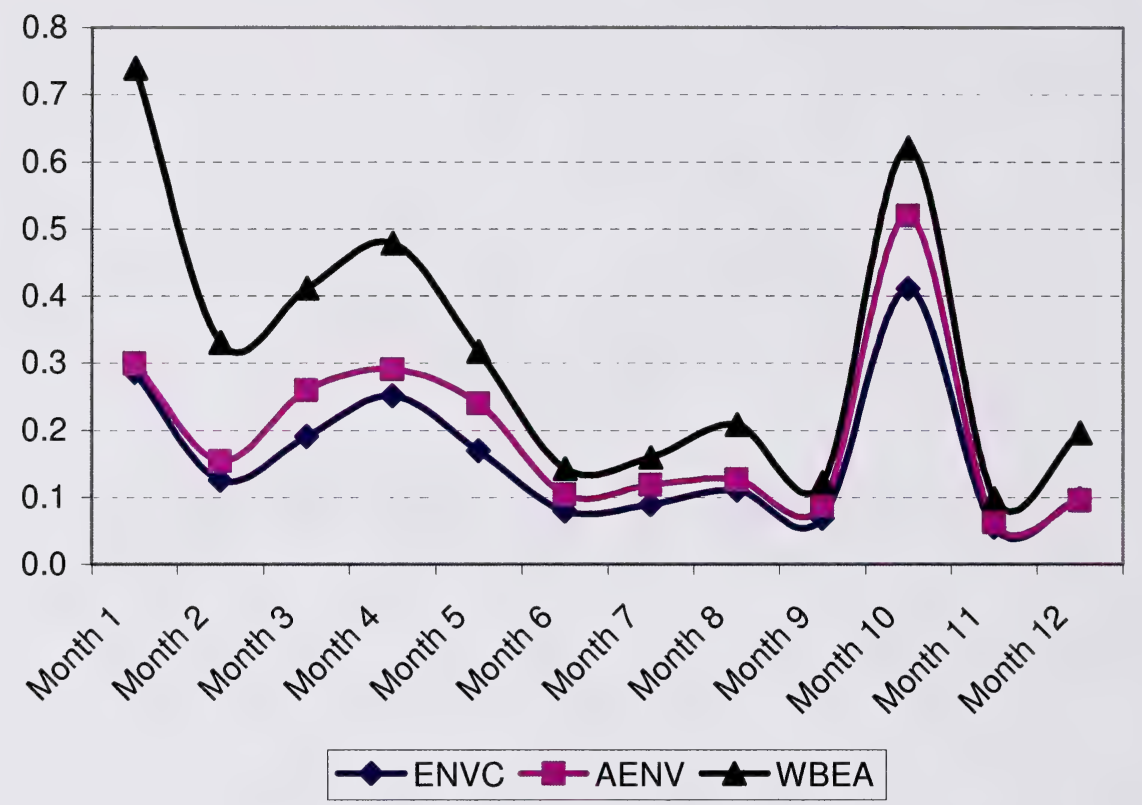

Figure 6. Monthly nitric acid $\left(\mathrm{HNO}_{3}\right)$ dry deposition for the period January to December 2003 at WBEA Fort McKay air monitoring station AMS \#1 (expressed in units of $\mathrm{kg} \mathrm{HNO}_{3} / \mathrm{ha} / \mathrm{month}$ ).

$($ ENVC $=$ Environment Canada method; AENV = Alberta Environment method; WBEA = Wood Buffalo Environmental Association method) 


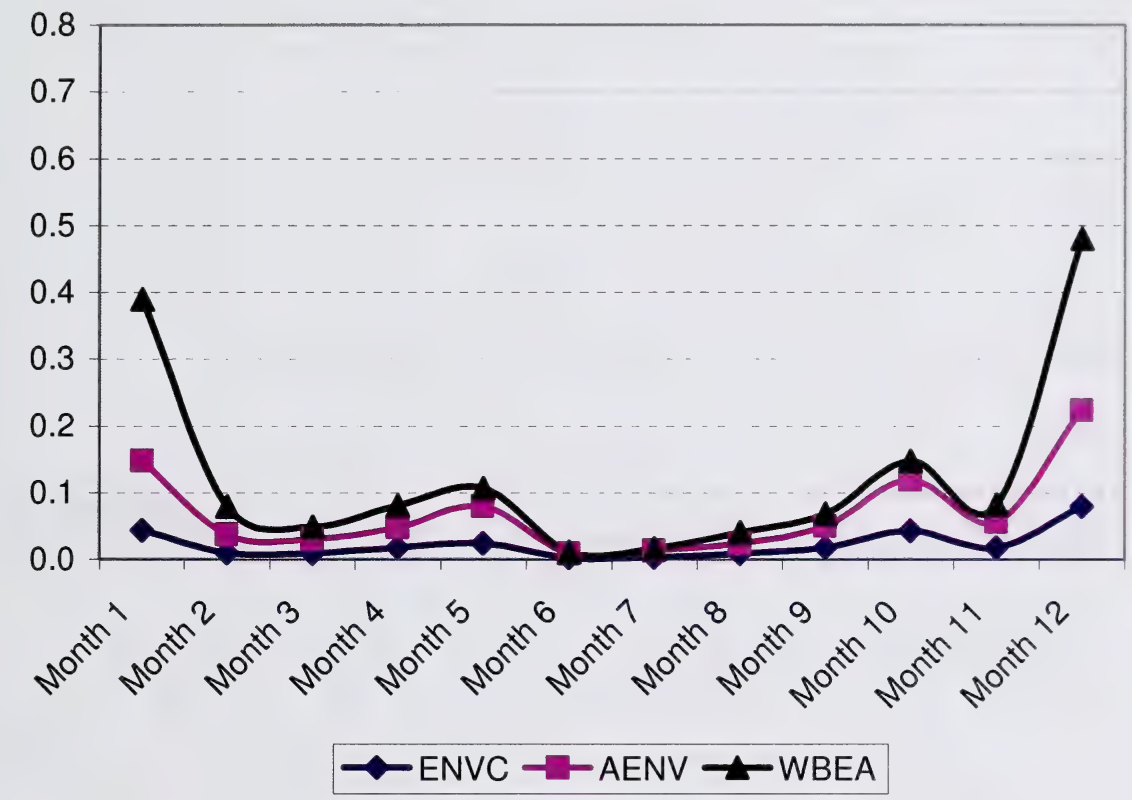

Figure 7. Monthly nitrous acid $\left(\mathrm{HNO}_{2}\right)$ dry deposition for the period January to December 2003 at WBEA Fort McKay air monitoring station AMS \#1 (expressed in units of $\mathrm{kg} \mathrm{HNO} / \mathrm{ha} /$ month).

$(\mathrm{ENVC}=$ Environment Canada method $; \mathrm{AENV}=$ Alberta Environment method;

WBEA $=$ Wood Buffalo Environmental Association method) 


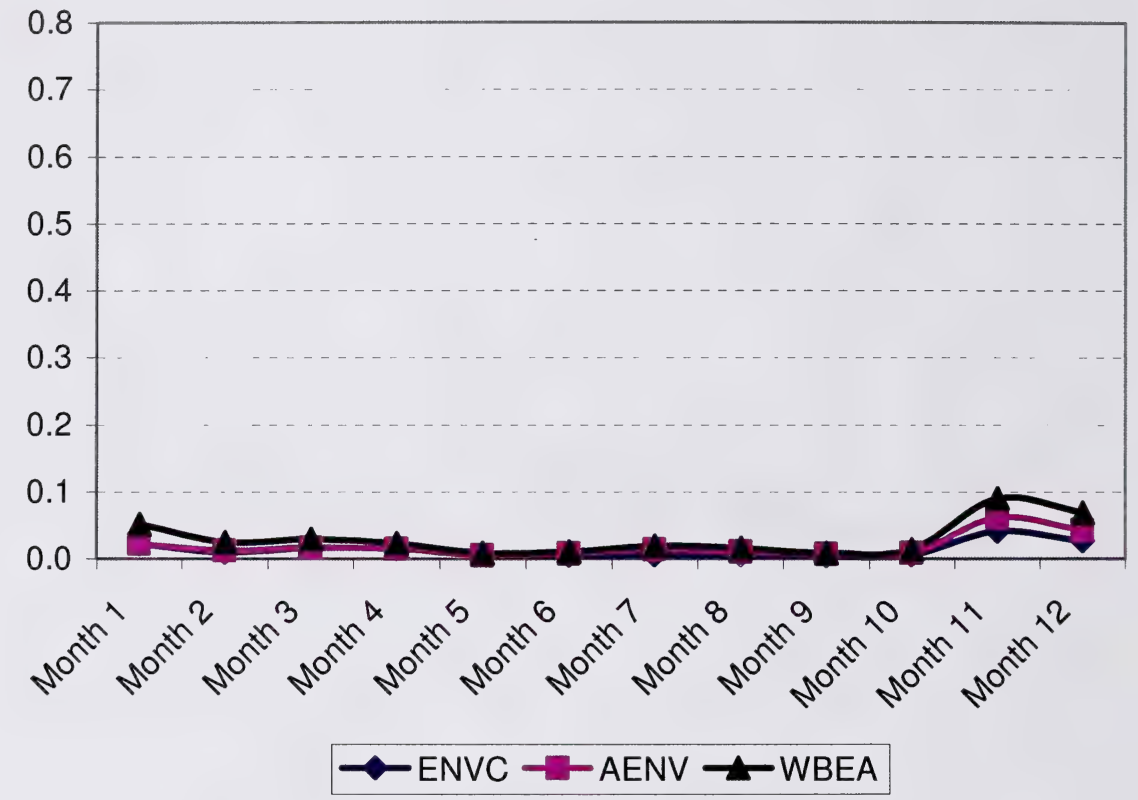

Figure 8. Monthly nitrate $\left(\mathrm{NO}_{3}{ }^{-}\right)$dry deposition for the period January to December 2003 at WBEA Fort McKay air monitoring station AMS \#1 (expressed in units of $\mathrm{kg} \mathrm{NO}_{3}{ }^{-} / \mathrm{ha} /$ month).

$(\mathrm{ENVC}=$ Environment Canada method; $\mathrm{AENV}=$ Alberta Environment method; WBEA = Wood Buffalo Environmental Association method) 


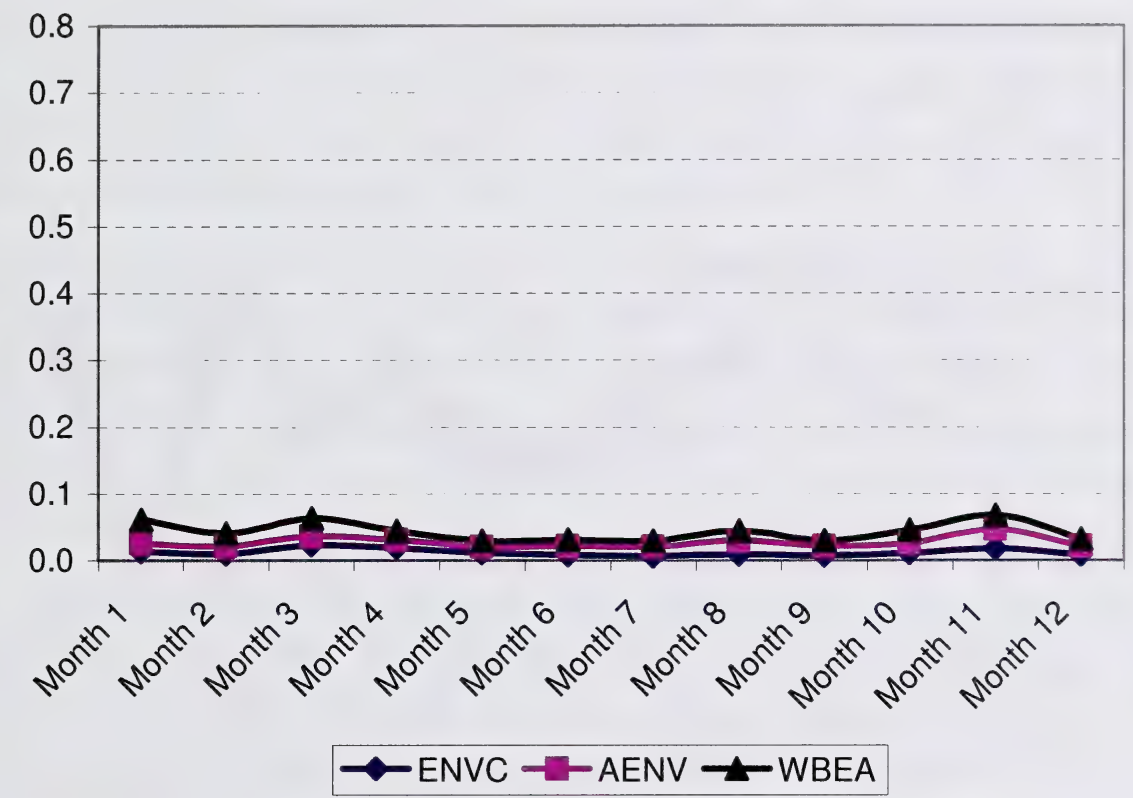

Figure 9. Monthly ammonium $\left(\mathrm{NH}_{4}{ }^{+}\right)$dry deposition for the period January to December 2003 at WBEA Fort McKay air monitoring station AMS \#1 (expressed in units of $\mathrm{kg} \mathrm{NH}_{4}{ }^{+} / \mathrm{ha} /$ month).

$($ ENVC $=$ Environment Canada method $; \mathrm{AENV}=$ Alberta Environment method; WBEA $=$ Wood Buffalo Environmental Association method) 


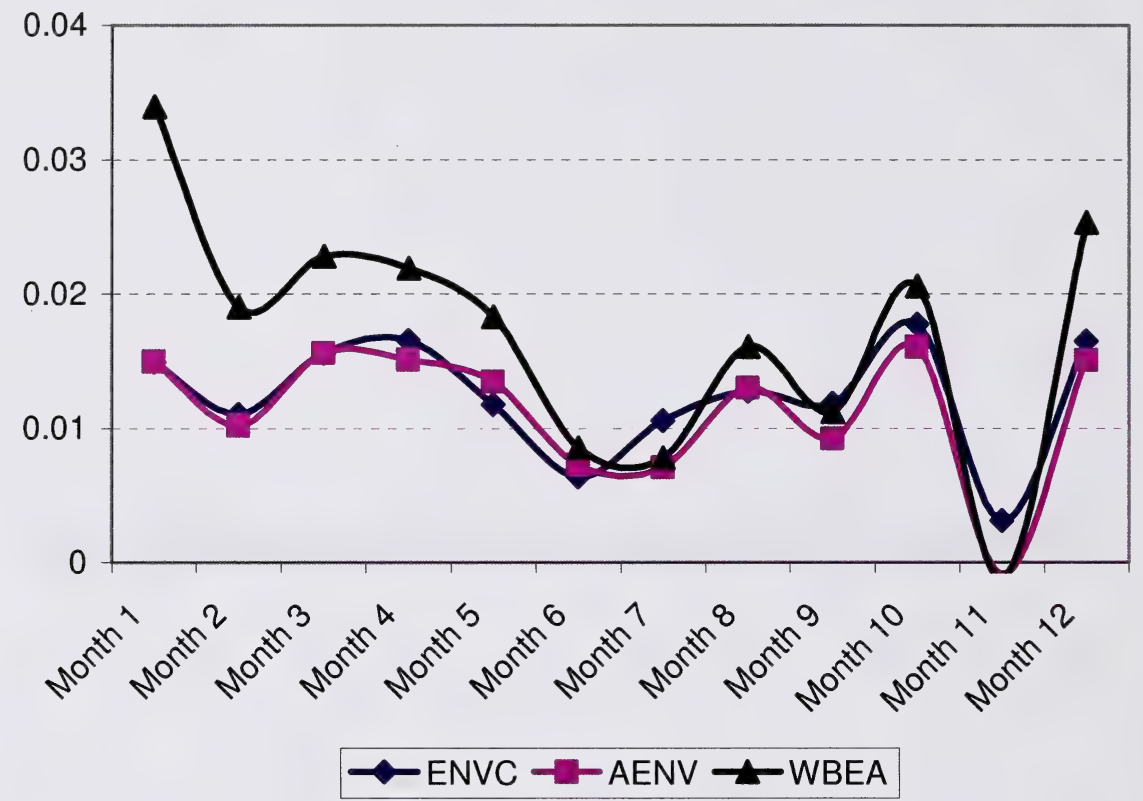

Figure 10. Monthly potential acid input (PAI) values associated with dry species for the period January to December 2003 at WBEA Fort McKay air monitoring station AMS \#1 (expressed in units of $\mathrm{kg} \mathrm{H}^{+} / \mathrm{ha} / \mathrm{month}$ ).

$(\mathrm{ENVC}=$ Environment Canada method $; \mathrm{AENV}=$ Alberta Environment method; WBEA = Wood Buffalo Environmental Association method) 
It is observed that ENVC model parameters have more boundary conditions (i.e. cut-off points and lower/upper limits) associated with their use (Appendix II) compared to the AENV model (Appendix I). Although not shown, it was observed that the AENV model had much greater variability associated with hourly model outputs. This may partially explain a net negative total PAI rate during the $11^{\text {th }}$ month for the 2003 dataset. At this time the influence of assigning additional boundary conditions associated with AENV model input parameters on variability associated with model outputs is unknown. Further testing would be required to better understand whether this has an ability to improve AENV model performance relative to the ENVC model.

Annual total PAI rates associated with dry species at the Fort McKay site using the 2003 dataset were $0.15 \mathrm{~kg} \mathrm{H}^{+} / \mathrm{ha} / \mathrm{yr}$ (ENVC method), $0.14 \mathrm{~kg} \mathrm{H}^{+} / \mathrm{ha} / \mathrm{yr}$ (AENV method), and $0.20 \mathrm{~kg} \mathrm{H}^{+} / \mathrm{ha} / \mathrm{yr}$ (WBEA method). The higher annual rate associated with dry species observed for the WBEA method relative to the other methods is entirely consistent with higher individual species deposition rates observed in Figures 4 to 9 .

Limited data exist to enable comparisons of these results with other observations. Environment Canada (2004) reported on modeling activities in the 2004 Alberta-wide acid deposition assessment. Annual average concentrations and annual depositions of sulphur species were calculated for a $1^{\circ}$ by $1^{\circ}$ latitude-longitude grid area where the Fort McKay site is located using the REgional Lagrangian Acid Deposition (RELAD) model. Modeling was undertaken for the 1971-2000 period using 30 years of meteorological data and 1995 emissions.

Environment Canada (2004) presented data that indicate a 1971 to 2000 (30-yr) mean annual sulphur species dry deposition rate range of 0.06 to $0.08 \mathrm{~kg} \mathrm{H}^{+} / \mathrm{ha} / \mathrm{yr}$ for a $1^{\circ}$ by $1^{\circ}$ latitude-longitude grid area where the Fort McKay site is located. Although these results are not directly comparable, annual total sulphur species dry deposition rates at the Fort McKay site using the 2003 dataset were $0.053 \mathrm{~kg} \mathrm{H}^{+} / \mathrm{ha} / \mathrm{yr}$ (ENVC method), $0.044 \mathrm{~kg}$ $\mathrm{H}^{+} / \mathrm{ha} / \mathrm{yr}$ (AENV method), and $0.060 \mathrm{~kg} \mathrm{H}^{+} / \mathrm{ha} / \mathrm{yr}$ (WBEA method).

RWDI (2004) reported historical measured and predicted $\mathrm{NO}_{2}$ dry deposition rates for the Fort McKay site. RWDI (2004) reported an average measured $\mathrm{NO}_{2}$ dry deposition rate of $0.17 \mathrm{~kg} \mathrm{H}^{+} / \mathrm{ha} / \mathrm{yr}$ (2.33 $\left.\mathrm{kg} \mathrm{N} / \mathrm{ha} / \mathrm{yr}\right)$ for the 1999 to 2000 period. RWDI (2004) also reported an average modeled $\mathrm{NO}_{2}$ dry deposition rate of $0.14 \mathrm{~kg} \mathrm{H}^{+} / \mathrm{ha} / \mathrm{yr}(1.93 \mathrm{~kg}$ $\mathrm{N} / \mathrm{ha} / \mathrm{yr}$ ) for the 1998 to 2002 period. Annual total $\mathrm{NO}_{2}$ dry deposition rates at the Fort McKay site using the 2003 dataset were $0.10 \mathrm{~kg} \mathrm{H}^{+} / \mathrm{ha} / \mathrm{yr}$ (ENVC method), $0.08 \mathrm{~kg}$ $\mathrm{H}^{+} / \mathrm{ha} / \mathrm{yr}$ (AENV method), and $0.12 \mathrm{~kg} \mathrm{H}^{+} / \mathrm{ha} / \mathrm{yr}$ (WBEA method).

\subsubsection{Comparison of Inference Methods}

A general evaluation of model complexity and performance was recorded after work was completed with each inferential method for estimating dry deposition. A relative comparison of selective features of the three inference methods is presented in Table 3. Overall, it is the view of the report authors that the Environment Canada (ENVC) method is more sophisticated (complicated) given that it has the greatest number of input 
parameter requirements. Although not shown, it also required making a number of additional assumptions for some of the input parameters before modeling could be performed.

Table 3. Relative comparison of selective features of three inference methods for estimating dry deposition.

\begin{tabular}{|c|c|c|c|}
\hline & ENVC & AENV & WBEA \\
\hline Number of Parameters & 18 & 9 & 7 \\
\hline Relative level of complexity & High & Medium & Low \\
\hline $\begin{array}{l}\text { Relative computing time } \\
\text { requirements }\end{array}$ & High & Low & Low \\
\hline Method for calculating $R_{a}$ & Resistance model & Resistance model & Empirical equation \\
\hline Method for calculating $R_{b}$ & Resistance model & $\begin{array}{l}\text { Resistance model for } \\
\text { gas and empirical } \\
\text { constant for particles }\end{array}$ & $\begin{array}{l}\text { Resistance model for } \\
\text { gas and empirical } \\
\text { constant for particles }\end{array}$ \\
\hline \multirow{3}{*}{$\begin{array}{l}\text { Method for calculating } R_{c} \\
\text { Major assumptions required }\end{array}$} & Resistance model & Empirical constant & Empirical constant \\
\hline & $\begin{array}{l}\text { Meteorological data: } \\
\text { hourly precipitation } \\
\text { obtained from daily } \\
\text { totals in vague way }\end{array}$ & $\mathrm{n} / \mathrm{a}$ & $\mathrm{n} / \mathrm{a}$ \\
\hline & $\begin{array}{l}\text { Particle mass } \\
\text { distribution was } \\
\text { assumed }\end{array}$ & & \\
\hline $\begin{array}{l}\text { Number of land use categories } \\
\text { (LUCs) }\end{array}$ & 26 & 8 & 8 \\
\hline Seasons & $\begin{array}{l}\text { Function of latitude } \\
\text { and month }\end{array}$ & $\begin{array}{l}\text { Function of month, } \\
4 \text { seasons total }\end{array}$ & Function of month \\
\hline Number of gas species & 31 & 4 & 4 \\
\hline $\begin{array}{l}\text { Assumptions for particulate } \\
\text { species }\end{array}$ & $\begin{array}{l}\text { Based on distribution } \\
\text { assumptions }\end{array}$ & 7 & 7 \\
\hline Wetness correction & $\begin{array}{l}\text { Corrected based on } \\
\text { rain and dew } \\
\text { condition, respectively }\end{array}$ & $\begin{array}{l}\text { Time weighted by } \\
\text { combined surface } \\
\text { wetness and related } \\
\text { humidity conditions }\end{array}$ & $\begin{array}{l}\text { Corrected by } \\
\text { combined surface } \\
\text { wetness and related } \\
\text { humidity conditions }\end{array}$ \\
\hline Basis for leaf area index (LAI) & $\begin{array}{l}\text { Function of LUC and } \\
\text { season }\end{array}$ & $\mathrm{n} / \mathrm{a}$ & $\mathrm{n} / \mathrm{a}$ \\
\hline Basis for surface roughness & $\begin{array}{l}\text { Function of LUC and } \\
\text { Season }\end{array}$ & $\begin{array}{l}\text { Function of wind } \\
\text { speed and wind } \\
\text { direction deviation }\end{array}$ & $\mathrm{n} / \mathrm{a}$ \\
\hline Basis for stability condition & $\begin{array}{l}\text { Temperature difference } \\
\text { with temperature } \\
\text { gradient correction }\end{array}$ & $\begin{array}{l}\text { Temperature } \\
\text { difference }\end{array}$ & $\begin{array}{l}\text { Day vs. night } \\
\text { (unstable vs. stable } \\
\text { assumption) }\end{array}$ \\
\hline
\end{tabular}

ENVC $=$ Environment Canada method, $\mathrm{AENV}=$ Alberta Environment method, WBEA $=$ Wood Buffalo Environmental Association method $\mathrm{n} / \mathrm{a}=$ not applicable 
The Alberta Environment (AENV) method provided comparative results to the ENVC method based on the 2003 Fort McKay dataset. This method is less complicated compared to the ENVC method, and it requires less input data and computing time. Finally, the Wood Buffalo Environmental Association (WBEA) method is simple and straight-forward to program. However as discussed previously, this method yielded higher monthly deposition rates for most species modeled using the 2003 dataset.

Although a limited one-year dataset was available to evaluate these models, it is the view of the report authors that the AENV method offers a practical choice for routine computation of sulphur and nitrogen species dry deposition in Alberta. Further testing using different datasets elsewhere in Alberta is recommended to support this. If the ENVC method can be shown to provide comparative results to the AENV method using different datasets elsewhere in Alberta, it offers a logical choice for periodic use as a check on the AENV method.

\subsubsection{Relationships of Dry Deposition for Sulphur and Nitrogen Species}

Contributions of $\mathrm{SO}_{2}$ and $\mathrm{NO}_{2}$ deposition in total sulphur and nitrogen species deposition at the Fort McKay site were examined for the one-year dataset. Annual sulphur and nitrogen species deposition data were analyzed to determine the ratio of $\mathrm{SO}_{2}$ deposition to total sulphur species deposition and of $\mathrm{NO}_{2}$ deposition to total nitrogen species deposition. These results are presented in Table $4\left(\mathrm{SO}_{2}\right.$ to total $\mathrm{S}$ species deposition ratio) and Table $5\left(\mathrm{NO}_{2}\right.$ to total $\mathrm{N}$ species deposition ratio), respectively.

Table 4. Ratio of annual $\mathrm{SO}_{2}$ deposition to total sulphur species deposition at WBEA Fort McKay air monitoring station during 2003.

\begin{tabular}{|c|c|c|c|c|}
\hline \multirow[t]{2}{*}{ Method } & \multirow{2}{*}{$\begin{array}{c}\mathrm{SO}_{2} \\
\mathrm{~kg} \mathrm{~S} / \mathrm{ha} / \mathrm{yr}\end{array}$} & \multirow{2}{*}{$\begin{array}{c}\mathrm{SO}_{4}{ }^{2-} \\
\mathrm{kg} \mathrm{S} / \mathrm{ha} / \mathrm{yr}\end{array}$} & \multicolumn{2}{|c|}{$\mathrm{SO}_{2} / \mathrm{S}_{\text {tot }}$} \\
\hline & & & 2.4.3.1 & Ratio \\
\hline ENVC & 1.489 & 0.101 & \multicolumn{2}{|c|}{0.94} \\
\hline AENV & 0.975 & 0.222 & \multicolumn{2}{|c|}{0.82} \\
\hline WBEA & 1.197 & 0.361 & \multicolumn{2}{|c|}{0.77} \\
\hline
\end{tabular}

Note: $\frac{\mathrm{SO}_{2}}{\mathrm{~S}_{t o t}}$ Ratio $=\frac{\mathrm{SO}_{2}}{\mathrm{SO}_{2}+\mathrm{SO}_{4}^{2-}}$

$\mathrm{ENVC}=$ Environment Canada method

$\mathrm{AENV}=$ Alberta Environment method

WBEA = Wood Buffalo Environmental Association method

Results presented in Table 4 and 5 using the Alberta Environment method (AENV) are discussed here because previous work by WBK (2008) used the same method to estimate ratios at another acid deposition monitoring site in Alberta - Beaverlodge. Estimates of 
annual S species deposition for the Fort McKay site indicate that about $82 \%$ is in the form of gaseous $\mathrm{SO}_{2}$ with the remainder as particulate sulphate $(18 \%)$.

WBK (2008) reported on annual deposition loadings of S and N species during 1998 to 2002 at a former Alberta Environment Beaverlodge acid deposition monitoring site. The station was located west of Grande Prairie at an Agriculture and Agri-food Canada Research Farm. Estimates of annual S species deposition (Table 6) consistently showed that about $80 \%$ was in the form of gaseous $\mathrm{SO}_{2}$ with the remainder as particulate sulphate. These data compare well with that observed at Fort McKay during 2003 (82\%).

Table 5. Ratio of annual $\mathrm{NO}_{2}$ deposition to total nitrogen species deposition at WBEA Fort McKay air monitoring station during 2003.

\begin{tabular}{|c|c|c|c|c|c|c|c|}
\hline \multirow[t]{2}{*}{ Method } & \multirow{2}{*}{$\begin{array}{c}\mathrm{NO}_{2} \\
\mathrm{Kg} \mathrm{N} / \mathrm{ha} / \mathrm{yr}\end{array}$} & \multirow{2}{*}{$\begin{array}{c}\mathrm{HNO}_{3} \\
\mathrm{~kg} \mathrm{~N} / \mathrm{ha} / \mathrm{yr}\end{array}$} & \multirow{2}{*}{$\begin{array}{c}\mathrm{HNO}_{2} \\
\mathrm{~kg} \mathrm{~N} / \mathrm{ha} / \mathrm{yr}\end{array}$} & \multirow{2}{*}{$\begin{array}{c}\mathrm{NO}_{3}^{-} \\
\mathrm{kg} \mathrm{N} / \mathrm{ha} / \mathrm{yr}\end{array}$} & \multirow{2}{*}{$\begin{array}{c}\mathrm{NH}_{4}^{+} \\
\mathrm{kg} \mathrm{N} / \mathrm{ha} / \mathrm{yr}\end{array}$} & \multicolumn{2}{|c|}{$\mathrm{NO}_{2} / \mathrm{N}_{\text {tot }}$} \\
\hline & & & & & & 2.4.3.2 & Ratio \\
\hline ENVC & 1.368 & 0.430 & 0.083 & 0.038 & 0.112 & \multicolumn{2}{|c|}{0.67} \\
\hline AENV & 1.132 & 0.524 & 0.250 & 0.051 & 0.250 & \multicolumn{2}{|c|}{0.51} \\
\hline WBEA & 1.632 & 0.850 & 0.463 & 0.082 & 0.404 & \multicolumn{2}{|c|}{0.48} \\
\hline
\end{tabular}

Note: $\frac{\mathrm{NO}_{2}}{\mathrm{~N}_{\text {tot }}}$ Ratio $=\frac{\mathrm{NO}_{2}}{\mathrm{NO}_{2}+\mathrm{HNO}_{3}+\mathrm{HNO}_{2}+\mathrm{NH}_{4}^{+}+\mathrm{NO}_{3}^{-}}$

$\mathrm{ENVC}=$ Environment Canada method

AENV $=$ Alberta Environment method

WBEA = Wood Buffalo Environmental Association method

Estimates of annual $\mathrm{N}$ species deposition at the Fort McKay site showed that about $51 \%$ was from $\mathrm{NO}_{2}$ with the remainder as $\mathrm{HNO}_{3}$ and $\mathrm{HNO}_{2}(35 \%)$ and particulate ammonium and nitrate $(<14 \%)$. Estimates of annual $\mathrm{N}$ species deposition at the Beaverlodge site (Table 7) showed that about 35 to $50 \%$ was from $\mathrm{NO}_{\mathrm{x}}\left(\mathrm{NO}+\mathrm{NO}_{2}\right)$ with the remainder as $\mathrm{HNO}_{3}$ and $\mathrm{HNO}_{2}(\sim 40$ to $60 \%)$ and particulate ammonium and nitrate $(<10 \%)$ (WBK, 2008). Again, results for the Beaverlodge site on the same order as that observed at the Fort McKay site.

WBK (2008) reported on work of Peake and Davidson (1990) related to estimated annual dry deposition of $\mathrm{N}$ species $\left(\mathrm{NO}_{\mathrm{x}}, \mathrm{HNO}_{2}, \mathrm{HNO}_{3}\right.$, and $\left.\mathrm{NO}_{3}{ }^{-}\right)$in the south western region of Alberta. This region stretches east from the Great Divide of the Rocky Mountains to the plains of southern Alberta, $80 \mathrm{~km}$ east of Calgary, as discussed by Peake and Davidson (1990). These estimates were based upon measurements made at Crossfield east and west, and Fortress Mountain monitoring sites during 1985 to 1987 as part of the Alberta Government/Industry Acid Deposition Research Program (ADRP). Using data reported by Peake and Davidson (1990). WBK (2008) estimated that about $32 \%$ of $\mathrm{N}$ deposition was from $\mathrm{NO}_{\mathrm{x}}\left(\mathrm{NO}+\mathrm{NO}_{2}\right)$ with the remainder as nitric and nitrous acid $(\sim 63 \%)$ and particulate nitrate $(\sim 5 \%)$. 
Table 6. Ratio of annual $\mathrm{SO}_{2}$ deposition to total sulphur species deposition at Beaverlodge, Alberta (after WBK, 2008).

\begin{tabular}{cccc}
\hline & $\mathrm{SO}_{2}$ & $\mathrm{SO}_{4}{ }^{2-}$ & $\mathrm{SO}_{2} / \mathrm{S}_{\text {tot }}$ \\
Year & $\mathbf{k g ~ S} / \mathbf{h a} / \mathbf{y r}$ & $\mathbf{k g ~ S} / \mathbf{h a} / \mathbf{y r}$ & $\mathbf{2 . 4 . 3 . 3} \quad$ Ratio \\
\hline 1998 & 0.368 & 0.083 & $\mathbf{0 . 8 2}$ \\
1999 & 0.305 & 0.072 & $\mathbf{0 . 8 1}$ \\
2000 & 0.294 & 0.064 & $\mathbf{0 . 8 2}$ \\
2001 & 0.317 & 0.069 & $\mathbf{0 . 8 2}$ \\
2002 & 0.317 & 0.072 & $\mathbf{0 . 8 1}$ \\
\hline \multirow{2}{*}{ Note: } & $\frac{\mathrm{SO}_{2}}{\mathrm{~S}_{\text {tot }}}$ Ratio $=\frac{\mathrm{SO}_{2}}{\mathrm{SO}_{2}+\mathrm{SO}_{4}^{2-}}$ &
\end{tabular}

Bytnerowicz et al. (1999) as cited in Bytnerowicz et al. (2005) reported that $\mathrm{HNO}_{3}$ typically provides more than $60 \%$ of all dry-deposited $\mathrm{N}$ species in mixed conifer forests of the Los Angeles Basin mountain range of California.

Table 7. Ratio of annual $\mathrm{NO}_{\mathrm{x}}$ deposition to total nitrogen species deposition at Beaverlodge, Alberta (after WBK, 2008).

\begin{tabular}{cccccccc}
\hline & $\mathrm{NO}_{x}$ & $\mathrm{HNO}_{3}$ & $\mathrm{HNO}_{2}$ & $\mathrm{NO}_{3}{ }^{-}$ & $\mathrm{NH}_{4}{ }^{+}$ & $\mathrm{NO}_{x} / \mathbf{N}_{\text {tot }}$ \\
Year & $\mathrm{Kg} \mathrm{N} / \mathbf{h a} / \mathbf{y r}$ & $\mathbf{k g ~ N} / \mathbf{h a} / \mathbf{y r}$ & $\mathbf{k g ~ N} / \mathbf{h a} / \mathbf{y r}$ & $\mathbf{k g ~ N} / \mathbf{h a} / \mathbf{y r}$ & $\mathbf{k g ~ N} / \mathbf{h a} / \mathbf{y r}$ & $\mathbf{2 . 4 . 3 . 4}$ & Ratio \\
\hline 1998 & 0.617 & 0.370 & 0.097 & 0.030 & 0.077 & $\mathbf{0 . 5 2}$ \\
1999 & 0.556 & 0.482 & 0.051 & 0.034 & 0.060 & $\mathbf{0 . 4 7}$ \\
2000 & 0.551 & 0.412 & 0.064 & 0.029 & 0.054 & $\mathbf{0 . 5 0}$ \\
2001 & 0.572 & 0.600 & 0.098 & 0.035 & 0.050 & $\mathbf{0 . 4 2}$ \\
2002 & 0.679 & 0.952 & 0.229 & 0.041 & 0.040 & $\mathbf{0 . 3 5}$ \\
\hline
\end{tabular}

Note: $\mathrm{NO}_{\mathrm{x}} / \mathrm{N}_{\text {tot }}$ Ratio $=\frac{\mathrm{NO}_{x}}{\mathrm{NO}_{x}+\mathrm{HNO}_{3}+\mathrm{HNO}_{2}+\mathrm{NH}_{4}^{+}+\mathrm{NO}_{3}^{-}}$ 


\subsection{FINDINGS AND RECOMMENDATIONS}

1. Complete sulphur and nitrogen gaseous and particulate species and meteorological data for a one-year period (2003) from the Wood Buffalo Environmental Association Fort McKay air monitoring station were evaluated using the three methods. All three methods showed a similar ability to represent variation in dry deposition rates for individual species from month to month.

2. The WBEA method yielded higher monthly deposition rates for most species modeled $\left(\mathrm{SO}_{4}{ }^{2-}, \mathrm{NO}_{2}, \mathrm{HNO}_{3}, \mathrm{HNO}_{2}\right.$, and $\left.\mathrm{NH}_{4}{ }^{+}\right)$compared to the AENV and ENVC methods. The WBEA method also yielded higher potential acid input (PAI) values associated with dry species compared to the AENV and ENVC methods during winter and spring. The WBEA method gave similar PAI values associated with dry species during summer and fall. A simpler computational approach for aerodynamic and surface resistance terms in the WBEA method may partially explain differences observed during winter and spring. Further testing would be required to better understand whether this is the case.

3. Annual total PAI associated with dry species for 2003 was $0.14 \mathrm{~kg} \mathrm{H}^{+} / \mathrm{ha} / \mathrm{yr}$ (AENV method), $0.15 \mathrm{~kg} \mathrm{H}^{+} / \mathrm{ha} / \mathrm{yr}$ (ENVC method), and $0.20 \mathrm{~kg} \mathrm{H}^{+} / \mathrm{ha} / \mathrm{yr}$ (WBEA method). The higher annual rate associated with dry species observed for the WBEA method relative to other methods is consistent with higher monthly deposition rates for individual species. While the AENV and ENVC methods yielded comparable monthly PAI values associated with dry species, it is observed that ENVC input parameters have more boundary conditions (i.e. cut-off points and lower/upper limits) associated with their use compared to AENV input parameters.

4. The ENVC method is more complicated given that it has the greatest number of input parameter requirements. A number of additional assumptions for some of the input parameters are also required before modeling can be performed. The AENV method provided comparative results to the ENVC method. The AENV method is less complicated compared to the ENVC method, and it requires less input data and computing time. The WBEA method is simple and straightforward to use. However, this method yielded higher monthly deposition rates for most species modeled compared to the other methods using the 2003 dataset.

5. The dataset used to evaluate the methods was short - one year - and month to month variation or lack of variation in species deposition rates observed using each method does not necessarily provide an indication of what may happen in other years. Although only a one-year dataset was available for evaluation, results support that the AENV method offers a practical choice for routine computation of sulphur and nitrogen species dry deposition in Alberta. Further testing using different datasets elsewhere in Alberta is recommended to support 
this. If the ENVC method can be shown to provide comparable results to the AENV method using different datasets, it would offer a logical choice for periodic use as a check on the AENV method.

6. Evaluation of contributions of $\mathrm{SO}_{2}$ and $\mathrm{NO}_{2}$ deposition in total sulphur and nitrogen species deposition at the Fort McKay site indicated that about $82 \%$ is in the form of gaseous $\mathrm{SO}_{2}$ with the remainder as particulate $\mathrm{SO}_{4}{ }^{2-}(18 \%)$. These results are comparable to annual deposition loadings of sulphur species during 1998 to 2002 at the former Alberta Environment Beaverlodge acid deposition monitoring site $\left(80 \%\right.$ in the form of gaseous $\mathrm{SO}_{2}$ and $20 \%$ as particulate $\mathrm{SO}_{4}{ }^{2-}$ ).

Estimates of annual nitrogen species deposition at the Fort McKay site indicated that $\sim 51 \%$ was from $\mathrm{NO}_{2}$ with the remainder as $\mathrm{HNO}_{3}$ and $\mathrm{HNO}_{2}(35 \%)$ and particulate $\mathrm{NH}_{4}{ }^{+}$and $\mathrm{NO}_{3}{ }^{-}(<14 \%)$. Estimates of annual nitrogen species deposition at the Beaverlodge site during 1998 to 2002 showed that about 35 to $50 \%$ was from $\mathrm{NO}$ and $\mathrm{NO}_{2}$ with the remainder as $\mathrm{HNO}_{3}$ and $\mathrm{HNO}_{2}$ (40 to $60 \%$ ) and particulate $\mathrm{NH}_{4}{ }^{+}$and $\mathrm{NO}_{3}{ }^{-}(<10 \%)$.

7. Future work evaluating these inference methods should consider the influence of assigning additional boundary conditions to AENV model input parameters on variability associated with model outputs. Specifically, assigning boundary conditions to AENV input parameters consistent with default ENVC model assumptions should be investigated to better understand whether these changes have the ability to improve AENV model performance relative to the ENVC model. 


\subsection{REFERENCES}

Brook, J., Zhang, L., Di Giovannic, F., and Padro, J. 1999a. Description and evaluation of a model of deposition velocities for routine estimates of air pollutant dry deposition over North America. Part I: model development. Atmos. Environ., 33: 5037-5051.

Brook, J., Zhang, L., Li, Y., and Johnson, D.. 1999b. Description and evaluation of a model of deposition velocities for routine estimates of air pollutant dry deposition over North America. Part II: review of past measurements and model results. Atmos. Environ., 33: 5053-5070.

Bytnerowicz, A., Sanz, M., Arbaugh, M., Padgett, P., Jones, D., and Davila, A. 2005. Passive sampler for monitoring ambient nitric acid $\left(\mathrm{HNO}_{3}\right)$ and nitrous acid $\left(\mathrm{HNO}_{2}\right)$ concentrations. Atmos. Environ., 39: 2655-2660.

Bytnerowicz, A., Tausz, M., Alonso, R., Jones, D., Johnson, R., and Grulke, N. 2002a. Summer-time distribution of air pollutants in Sequoia National Park, California. Environ. Pollut., 188: 187-203.

Bytnerowicz, A., Parker, D., and Padgett, P. 2002b. Vertical distribution of ozone and nitric acid vapor on the Mammoth Mountain, Eastern Sierra Nevada, California. Sci. World J., 2: 1-9.

Bytnerowicz, A., Padgett, P., Arbaugh, M., Parker, D., and Jones, D. 2001. Passive sampler for measurements of atmospheric nitric acid vapor $\left(\mathrm{HNO}_{3}\right)$ concentrations. Sci. World J., 1: 815-822.

Canadian Oil Sands Trust (COST). 2006. Canadian Oil Sands Trust, Calgary, AB. Available at: http://www.cos-trust.com/asset/ (accessed February 2006).

Cheng, L., Bates, D.L., and Myrick, B. 2001. Acidic Deposition Monitoring and Calculations in Alberta, Draft 5. Alberta Environment, Edmonton, AB. 28 pp.

Cheng, L., McDonald, K., Fox, D., and Angle, R. 1997, Total Potential Acid Input in Alberta. Alberta Environmental Protection, Edmonton, AB. 27 pp.

Clarke, J.F., Edgerton, E.S., and Martin, B.E. 1997. Dry deposition calculations for the Clean Air Status and Trends Network. Atmos. Environ., 31: 3667-3678.

EPCM Associates Ltd. (EPCM). 2002. Operational Manual for TEEM DEP Model Estimation of Dry Acidic Deposition at TEEM Passive Monitoring Sites. Report prepared for Wood Buffalo Environmental Association Terrestrial Environmental Effects Monitoring (TEEM) Committee, Fort McMurray, AB. April 2002. 13 pp 
EPCM. 2000. Evaluation of Passive Sampling Systems at TEEM Jack Pine Monitoring sites. Part II. Dry Deposition of SO2. Report prepared for Wood Buffalo Environmental Association Terrestrial Environmental Effects Monitoring (TEEM) Committee, Fort McMurray, AB. 13 November 2000. 24 pp.

Erisman, J.W., Van Pul, A., and Wyers, P. 1994. Parameterization of surface resistance of the quantification of atmospheric deposition of acidifying pollutants and ozone. Atmos. Environ., 28: 2595-2607.

Environment Canada (ENVC). 2004. 2004 Canadian Acid Deposition Science Assessment. En4-46/2004E-MRC. Environment Canada, Meteorological Service of Canada (MSC), Ottawa, ON. Available at: http://www.mscsmc.ec.gc.ca/saib/acid/acid_e.html (accessed January 2006).

Giorgi, F. 1988. Dry deposition velocities of atmospheric aerosols as inferred by applying a particle dry deposition parameterization to a general circulation model. Tellus, 40B: $23-41$.

Hicks, B.B., Baldoechi, D.D., Meyers T.P., Hosker Jr R.P., and Matt, D.R. 1987. A preliminary multiple resistance routine for deriving dry deposition velocities from measured quantities. Wat. Air Soil Pollut., 26: 311-330.

Hicks, B.B. 1982. Critical Assessment Document on Acid Deposition (Chapter VII-Dry Deposition). ATDL Contribution File No. 81/24. Atmospheric Turbulence and Diffusion Laboratory, National Oceanic and Atmospheric Administration, Oak Ridge, TN.

Howard, P.H. and Meylan, W.M. 1997. Handbook of Physical Properties of Organic Chemicals. CRC Lewis Publishers, Boca Raton, FL.

Lovett, G.M. 1994. Atmospheric deposition of nutrients and pollutants in North America: an ecological perspective. Ecol. Appl., 4: 629-650.

Padro, J. 1996. Summary of ozone dry deposition velocity measurements and model estimates over vineyard, cotton, grass and deciduous forest in summer. Atmos. Environ., 30: 2363-2369.

Padro, J., den Hartog, G., and Neumann, H.H. 1991. An investigation of the ADOM dry deposition module using summertime $\mathrm{O}_{3}$ measurements above a deciduous forest. Atmos. Environ., 25: 1689-1704.

Peake, E. and Davidson, C.I. 1990. Wet and dry deposition of air pollutants in Alberta. In: Acidic Deposition: Sulphur and Nitrogen Oxides, A.H. Legge and S.V. Krupa (ed.). Lewis Publishers, Chelsea, MI. pp. 381-412. 
Peters, K. and Eiden, R. 1992. Modelling the dry deposition velocity of aerosols particles to a Spruce forest. Atmos. Environ., 26: 2555-2564.

Pleim, J., Venkatram, A., and Yamartino, R. 1984. ADOM/TADAP Model Development Program. ERT P-B980-520. Prepared for OME, AES of Canada and the Umweltbundesamt, West Germany.

Ruijgrok, W., Tieben, H., and Eisinga, P., 1997. The dry deposition of particles to a forest canopy: a comparison of model and experimental results. Atmos. Environ., 31: 399-415.

RWDI West Inc. (RWDI). 2004. $\mathrm{NO}_{\mathrm{x}}$ Dispersion and Chemistry Assumptions in the CALPUFF Model. Draft report prepared for $\mathrm{NO}_{x} \mathrm{SO}_{x}$ Management Working Group, Cumulative Effects Management Association, Fort McMurray, AB. October 2004.

Sander, R. 1999. Compilation of Henry's Law Constants for Inorganic and Organic Species of Potential Importance in Environmental Chemistry (version 3). Available at: http://www.mpchmainz.mpg.de/ sander/res/henry.html.

Slinn, W.G.N. 1982. Predictions for particle deposition to vegetative surfaces. Atmos. Environ., 16: 1785-1794.

US Environmental Protection Agency (EPA). 2001. Frequently Asked Questions About Acid Deposition. EPA-453/R-01-009. US EPA Office of Air Quality, Research Triangle Park, NC 27711. September 2001.

Wesely, M.L. and Hicks, B.B. 2000. A review of the current status of knowledge on dry deposition. Atmos. Environ., 34: 2261-2282.

Wesley, M.L. and Hicks, B.B. 1977. Some factors that affect the deposition rates of sulphur dioxide and similar gases on vegetation. J. Air Poll. Cont. Assoc., 27: 1110-1116.

Wesely, M.L., Cook, D.R., Hart, R.L., and Speer, R.R. 1985. Measurements and parameterization of particle sulphur deposition over grass. J. Geophysical Res., 90: 2131-2143.

WBK \& Associates Inc. (WBK). 2008. Review and Assessment of Methods for Monitoring and Estimating Dry Deposition in Alberta. Report prepared for Alberta Environment, Edmonton, AB. June 2008. 54 pp.

Zhang, L., Brook, J., and Vet, R. 2003a. Evaluation of a non-stomatal resistance parameterization for $\mathrm{SO}_{2}$ dry deposition. Atmos. Environ., 37: 2941-2947. 
Zhang, L., Brook, J., and Vet, R. 2003b. A revised parameterization for gaseous dry deposition in air-quality models. Atmos. Chem. Phys. Discuss, 3: 1777-1804.

Zhang, L., Moran, M., Makar, P., Brook, J., and Gong, S. 2002a. Modelling gaseous dry deposition in AURAMS - A Unified Regional Air-quality Modelling System. Atmos. Environ., 36: 537-560.

Zhang, L., Brook, J., and Vet, R. 2002b. On ozone dry deposition with emphasis on nonstomatal uptake and wet canopies. Atmos. Environ. 36: 4787-4799.

Zhang, L., Gong, S.L., Padro, J., and Barrie, L. 2001a. A size-segregated particle dry deposition scheme for an atmospheric aerosol module. Atmos. Environ., 35: 549560 .

Zhang, L., Moran, M.D., Makar, P.A., Brook, J.R., and Gong, S. 2001b. Modelling gaseous dry deposition in AURAMS: a unified regional air-quality modelling system. Atmos. Environ., 36: 537-560. 


\section{APPENDIX I}

\section{Alberta Environment Calculation Methods for Gases and Particulates}

(after Cheng et al., 2001)

\section{Parameters:}

PAI Potential Acid Input $\left(\mathrm{kg} \mathrm{H}^{+} / \mathrm{ha} / \mathrm{yr}\right)$

[X] concentration of $\mathrm{X}$ chemical species deposited $(\mathrm{kg} / \mathrm{ha} / \mathrm{yr})$

F dry deposition flux $\left(\mu \mathrm{g} / \mathrm{m}^{2} / \mathrm{s}\right)$

$\mathrm{V}_{\mathrm{d}} \quad$ deposition velocity $(\mathrm{m} / \mathrm{s})$

C concentration $\left(\mu \mathrm{g} / \mathrm{m}^{3}\right)$

$\mathrm{R}_{\mathrm{a}} \quad$ aerodynamic resistance $(\mathrm{s} / \mathrm{m})$

$\mathrm{R}_{\mathrm{b}} \quad$ boundary-layer resistance $(\mathrm{s} / \mathrm{m})$

$\mathrm{R}_{\mathrm{c}} \quad$ surface resistance $(\mathrm{s} / \mathrm{m})$

k von Karman constant (0.4)

$\mathrm{u}^{*} \quad$ friction velocity $(\mathrm{m} / \mathrm{s})$

$\mathrm{z} \quad$ reference height $(10 \mathrm{~m})$

$\mathrm{z}_{0} \quad$ surface roughness length (m)

$\psi \quad$ integrated stability correction term

L Monin-Obukhov length scale

u wind speed $(\mathrm{m} / \mathrm{s})$

$\sigma_{\theta} \quad$ standard deviation of wind direction (rad)

$\mathrm{R}_{\mathrm{i}} \quad$ Bulk Richardson number

g gravitational acceleration $\left(9.81 \mathrm{~m} / \mathrm{s}^{2}\right)$

$\mathrm{T}_{\mathrm{d}} \quad$ temperature difference between 10 and $2 \mathrm{~m}\left(\mathrm{~T}_{10}-\mathrm{T}_{2}\right)$

$\mathrm{T}_{2} \quad$ temperature at $2 \mathrm{~m}$ (Kelvin)

$\mathrm{H} \quad$ sensible heat flux $\left(\mathrm{w} / \mathrm{m}^{2}\right)$

B defined equation described herein

$\eta \quad$ dynamic viscosity of air $\left(18.0 \times 10^{-6} \mathrm{~N}-\mathrm{s} / \mathrm{m}^{2}\right.$ at 1 atm and $\left.25^{\circ} \mathrm{C}\right)$

$\rho \quad$ density of air $\left(1.18 \mathrm{~kg} / \mathrm{m}^{3}\right.$ at $1 \mathrm{~atm}$ and $\left.25^{\circ} \mathrm{C}\right)$

D diffusion coefficient of the substance of interest $\left(\mathrm{cm}^{2} / \mathrm{s}\right)$

Pr Prandtl number for air (0.72)

$\eta / \rho D \quad$ Schmidt number

$\mathrm{RH} \quad$ relative humidity

SW soil wetness 


\section{Equations:}

$$
\begin{aligned}
& \mathbf{P A I}_{\text {dry }}=\frac{\left[\mathrm{SO}_{2}\right]}{64}+\frac{\left[\mathrm{NO}_{2}\right]}{46}+\frac{\left[\mathrm{HNO}_{2}\right]}{47}+\frac{\left[\mathrm{HNO}_{3}\right]}{63}+2 \frac{\left[\mathrm{SO}_{4}^{2-}\right]}{96}+\frac{\left[\mathrm{NO}_{3}^{-}\right]}{62}+\frac{\left[\mathrm{NH}_{4}^{+}\right]}{18} \\
& -\left(\frac{\left[\mathrm{K}^{+}\right]}{39}+\frac{\left[\mathrm{Na}^{+}\right]}{23}+2 \frac{\left[\mathrm{Ca}^{2+}\right]}{40}+2 \frac{\left[\mathrm{Mg}^{2+}\right]}{24}\right) \\
& \mathbf{F}=\mathrm{V}_{\mathrm{d}} \mathrm{C} \\
& \mathbf{V}_{\mathbf{d}}=\frac{1}{\left(R_{a}+R_{b}+R_{c}\right)}
\end{aligned}
$$

\section{Summary of Species Specific Deposition Velocity Formulae:}

$$
\left.\begin{array}{l}
V_{d\left(\mathrm{SO}_{2}\right)}=\frac{1}{R_{a}+R_{b\left(\mathrm{SO}_{2}\right)}+R_{c\left(\mathrm{SO}_{2}\right)}} \\
V_{d\left(\mathrm{NO}_{2}\right)}=\frac{1}{R_{a}+R_{b\left(\mathrm{NO}_{2}\right)}+R_{c\left(\mathrm{NO}_{X}\right)}} \\
V_{d\left(\mathrm{HNO}_{3}\right)}=\frac{1}{R_{a}+R_{b\left(\mathrm{SO}_{2}\right)}} \\
V_{d\left(\mathrm{HNO}_{2}\right)}=\frac{1}{R_{a}+R_{b(\mathrm{HNO})}} \\
V_{d\left(S O_{4}^{2-}, \mathrm{NH}_{4}^{+}\right)}=\frac{1}{R_{a}+R_{b\left(S O_{4}^{2-}\right)}} \\
V_{d\left(\mathrm{NO}_{3}^{-}, \mathrm{Ca}^{2+}, \mathrm{Mg}^{2+}, \mathrm{K}^{+}, \mathrm{Na}^{+}\right)}=\frac{1}{R_{a}+\left(0.5 \times R_{b\left(S O_{4}^{2-}\right)}\right)}
\end{array}\right\} \begin{aligned}
& \mathrm{R}_{\mathrm{c}} \text { is treated as being negligible for nitric and } \\
& \text { nitrous acid. }
\end{aligned}
$$

\section{Aerodynamic Resistance:}

$\mathrm{R}_{\mathrm{a}}=\frac{1}{k u^{*}}\left\{\ln \frac{z}{z_{0}}-\psi\left(\frac{z}{L}\right)\right\} \quad\left(\mathrm{R}_{\mathrm{a}}\right.$ is infinite and $\mathrm{V}_{\mathrm{d}}=0$ when $\mathrm{u}$ and $\mathrm{T}_{\mathrm{d}}$ are zero $)$

$\mathrm{u}^{*}=\frac{u \sigma_{\theta}}{1.9}$ (this relationship is used as an initial estimate of $\mathrm{u}^{*}$ to calculate $\mathrm{z}_{0}$, a more precise value of $u^{*}$ is calculated after $z_{0}$ is obtained - refer to below) 
$\mathrm{z}_{0}=z e^{-\left(\frac{0.4 u}{u^{*}}\right)}$ (calculated as a monthly average using data where the wind speed is $>6$ $\mathrm{m} / \mathrm{s}$ )

$\mathrm{R}_{\mathrm{i}}=\frac{g z T_{d}}{T_{2} u^{2}}$

A more precise value of $u^{*}$ calculated after $z_{0}$ is obtained (based on atmospheric conditions):

Stable conditions $\quad \mathbf{R}_{\mathbf{i}}>0 \quad u^{*}=k u\left\{\ln \left(\frac{z}{z_{0}}\right)(1+4.7 R i)\right\}^{-1}$

Unstable conditions $\quad \mathbf{R}_{\mathbf{i}}<0$

$$
u^{*}=\frac{k u}{\ln \left(\frac{z}{z_{0}}\right) \sqrt{1-\left\{\frac{9.4 R i}{1+(7.4 B)}\right\}}}
$$

Neutral conditions $\quad \mathbf{R}_{\mathbf{i}}=0 \quad u^{*}=\frac{k u}{\ln \left(\frac{z}{z_{0}}\right)}$

\section{Calculation of $\psi$ (based on atmospheric conditions):}

Stable conditions $\quad \boldsymbol{\psi}=-\frac{5 z}{L} \quad$ where $\mathbf{L}=\frac{T_{2} u^{* 3}}{k H g}$

Unstable conditions $\quad \psi=2 \ln \left\{\frac{1}{2}\left(1+\sqrt{1-\frac{15 z}{L}}\right)\right\}$

Neutral conditions $\quad \boldsymbol{\psi}=0$

\section{Calculation of $\mathbf{H}$ (based on atmospheric conditions):}

Neutral and Stable conditions $\mathbf{H}=\left\{\frac{u T_{d}}{0.74}\right\}\left\{\frac{k}{\ln \left(\frac{z}{z_{0}}\right)}\right\}^{2}\left\{\frac{1}{(1+4.7 R i)^{2}}\right\}$ 


$$
\begin{aligned}
& \text { Unstable conditions } \quad \mathbf{H}=\left\{\frac{u T_{d}}{0.74}\right\}\left\{\frac{k}{\ln \left(\frac{z}{z_{0}}\right)}\right\}\left\{1-\frac{9.4 R i}{(1+5.3 B)}\right\} \\
& \text { where } \mathbf{B}=9.4\left[\frac{k}{\ln \left(z / z_{0}\right)}\right]^{2}\left[\left|R_{i}\right| \frac{z}{z_{0}}\right]^{1 / 2}
\end{aligned}
$$

\section{Boundary Layer Resistance:}

$\mathbf{R}_{\mathrm{b}}$ (gases):

$\mathrm{R}_{\mathrm{b}}=R_{b}=\frac{2}{k u_{*}}\left(\frac{\eta}{\rho D} \times \frac{1}{\mathrm{Pr}}\right)^{2 / 3}$

$\mathrm{R}_{\mathrm{b}}=\frac{7.22}{u^{*}}$ for $\mathrm{SO}_{2}$ and $\mathrm{HNO}_{3}$

$\mathrm{R}_{\mathrm{b}}=\frac{6.18}{u^{*}}$ for $\mathrm{NO}_{2}$

$\mathrm{R}_{\mathrm{b}}=\frac{6.09}{u^{*}}$ for $\mathrm{HNO}_{2}$

\section{$\mathbf{R}_{\mathbf{b}}$ (particulates):}

$R_{b}$ values for particulate sulphate are obtained from scientific literature for daytime and nighttime as a function of surface type and weighted according to average day length for each month at a mid-Alberta latitude location $\left(54^{\circ} \mathrm{N}\right.$ latitude) after Cheng and Angle (1993) as cited in Cheng et al. (2001).

Boundary-Layer Resistance $(\mathrm{s} / \mathrm{cm})$ for Particulate Sulphate, Day Length Weighted

\begin{tabular}{|c|c|c|c|c|c|c|c|c|}
\hline \multirow[t]{2}{*}{ Surface Type } & \multicolumn{2}{|c|}{$\begin{array}{c}\text { Winter } \\
\text { (Dec, Jan, Feb) }\end{array}$} & \multicolumn{2}{|c|}{$\begin{array}{c}\text { Spring } \\
\text { (Mar, Apr, May) }\end{array}$} & \multicolumn{2}{|c|}{$\begin{array}{c}\text { Summer } \\
\text { (Jun, July, Aug) }\end{array}$} & \multicolumn{2}{|c|}{$\begin{array}{c}\text { Autumn } \\
\text { (Sep, Oct, Nov) }\end{array}$} \\
\hline & Dry & Wet & Dry & Wet & Dry & Wet & Dry & Wet \\
\hline Deciduous Forest & 16.9 & 0 & 5.4 & 0 & 1.3 & 0 & 3.2 & 0 \\
\hline Coniferous Forest & 2.5 & 0 & 2.7 & 0 & 1.9 & 0 & 2.3 & 0 \\
\hline Wetland/Swamp* & 20.4 & 0 & 3.8 & 0 & 2.6 & 0 & 3.2 & 0 \\
\hline Grassland* & 20.4 & 0 & 5.6 & 0 & 3.9 & 0 & 4.7 & 0 \\
\hline Cropland* & 20.4 & 0 & $9.0^{\dagger}$ & 0 & 3.9 & 0 & $7.9^{+}$ & 0 \\
\hline Urban $^{\S}$ & 33.9 & 0 & 10.9 & 0 & 2.6 & 0 & 6.3 & 0 \\
\hline
\end{tabular}
Averages at $54^{\circ} \mathrm{N}$ Latitude for the Middle of Each Month. 
Open Water

$$
0
$$

0

0

0

0

0

Snow/Ice

20.4

* in winter, wetland, grassland, and cropland treated as a snow surface. growth.

bare soil and senescent growth.

$\S$ consists of a mixture of deciduous forest and

buildings.

Day length Weighted Seasonal Average $\mathbf{R}_{\mathbf{b}}=\frac{\text { day length }}{24 h r s}\left(R_{b \text { day }}\right)+\left(1-\frac{\text { day length }}{24 h r s}\left(R_{b \text { night }}\right)\right)$

Day length $=0.133\left\{\cos ^{-1}\left(-\tan \left(55^{\circ}\right) \times \tan (\right.\right.$ Solar Declination $\left.)\right\}$

Solar Declination $=23.45\left\{\sin \left(\frac{360 \times(284+\text { Julian Day })}{365}\right)\right\}$

\section{Surface Resistance:}

Bulk surface resistance values are used from literature as a function of surface type, surface wetness, and incident radiation. Day length weighted average $\mathrm{R}_{\mathrm{c}}$ values for $\mathrm{SO}_{2}$ and $\mathrm{NO}_{2}$ are used from Voldner et al (1986), Arrit et al (1987) and Walcek et al (1986) as cited in Cheng et al. (2001):

Day Length Weighted Averages Bulk Surface Resistance (s/cm) for Sulphur Dioxide $\left(\mathrm{SO}_{2}\right)$ :

\begin{tabular}{lcccccccc}
\hline \multirow{2}{*}{ Surface Type } & \multicolumn{2}{c}{$\begin{array}{c}\text { Winter } \\
\text { (Dec, Jan, Feb) }\end{array}$} & \multicolumn{2}{c}{$\begin{array}{c}\text { Spring } \\
\text { (Mar, Apr, May) }\end{array}$} & \multicolumn{2}{c}{$\begin{array}{c}\text { Summer } \\
\text { (Jun, July, Aug) }\end{array}$} & \multicolumn{2}{c}{$\begin{array}{c}\text { Autumn } \\
\text { (Sep, Oct, Nov) }\end{array}$} \\
& Dry & Wet & Dry & Wet & Dry & Wet & Dry & Wet \\
\hline Deciduous Forest & 10 & 10 & 4.7 & 0 & 3.5 & 0 & 7.9 & 0.4 \\
Coniferous Forest & 5 & 5 & 4.1 & 0 & 3.5 & 0 & 4.9 & 0.2 \\
Wetland/Swamp* & 7 & 1 & 0.5 & 0 & 0.7 & 0 & 1 & 0.1 \\
Grassland* & 7 & 1 & 1 & 0 & 1.3 & 0 & 2 & 0.1 \\
Cropland* & 7 & 1 & 0 & 0 & 2 & 0 & $2 \ddagger$ & 0.1 \\
Urban & 10 & 2 & 10 & 0 & 10 & 0 & 10 & 0.1 \\
Open Water & 0 & 0 & 0 & 0 & 0 & 0 & 0 & 0 \\
Snow/Ice & 7 & 1 & - & - & - & - & - & - \\
\hline
\end{tabular}

* in winter, wetland, grassland, and cropland treated as a snow surface. growth.

bare soil and senescent growth.

$\S$ consists of a mixture of deciduous forest and

buildings.

Day Length Weighted Averages Bulk Surface Resistance $(\mathrm{s} / \mathrm{cm})$ for Nitrogen Dioxide $\left(\mathrm{NO}_{2}\right)$ :

\begin{tabular}{lcccccccc}
\hline \multirow{2}{*}{\begin{tabular}{l} 
Surface Type \\
\cline { 5 - 8 }
\end{tabular}} & \multicolumn{2}{c}{ Winter } & \multicolumn{2}{c}{ Spring } & \multicolumn{2}{c}{ Summer } & \multicolumn{2}{c}{ Autumn } \\
& (Dec, Jan, Feb) & \multicolumn{2}{c}{ (Mar, Apr, May) } & \multicolumn{2}{c}{ (Jun, July, Aug) } & \multicolumn{2}{c}{ (Sep, Oct, Nov) } \\
& Dry & Wet & Dry & Wet & Dry & Wet & Dry & Wet \\
\hline Deciduous Forest & 20.0 & 70.0 & 3.3 & 70.0 & 2.2 & 70.0 & 4.7 & 70.0
\end{tabular}




\begin{tabular}{lcccccccc} 
Coniferous Forest & 10.0 & 70.0 & 2.7 & 70.0 & 2.2 & 70.0 & 3.3 & 70.0 \\
Wetland/Swamp* & 50.0 & 70.0 & 12.1 & 70.0 & 11.5 & 70.0 & 12.9 & 70.0 \\
Grassland* & 50.0 & 70.0 & 3.3 & 70.0 & 3.3 & 70.0 & 6.6 & 70.0 \\
Cropland* & 50.0 & 70.0 & $3.3^{+}$ & 70.0 & 4.6 & 70.0 & 7.9 & 70.0 \\
Urban $^{\S}$ & 10.0 & 70.0 & 10.0 & 70.0 & 10.0 & 70.0 & 10.0 & 70.0 \\
Open Water & 70.0 & 70.0 & 70.0 & 70.0 & 70.0 & 70.0 & 70.0 & 70.0 \\
Snow/Ice & 50.0 & 70.0 & - & - & - & - & - & - \\
\hline
\end{tabular}

\footnotetext{
* in winter, wetland, grassland, and cropland treated as a snow surface. bare soil and active growth.

bare soil and senescent growth. $\$$ consists of a mixture of deciduous forest and buildings.
}

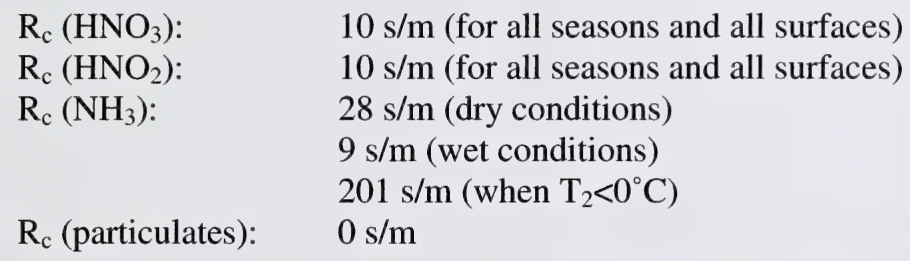

$\mathrm{R}_{\mathrm{c}}$ is calculated based on surface wetness criteria, such that it either represents a "total dry condition," "total wet condition," or "weighted wet condition" using the following flowchart, and relative humidity (RH) and surface wetness (SW) criteria: 


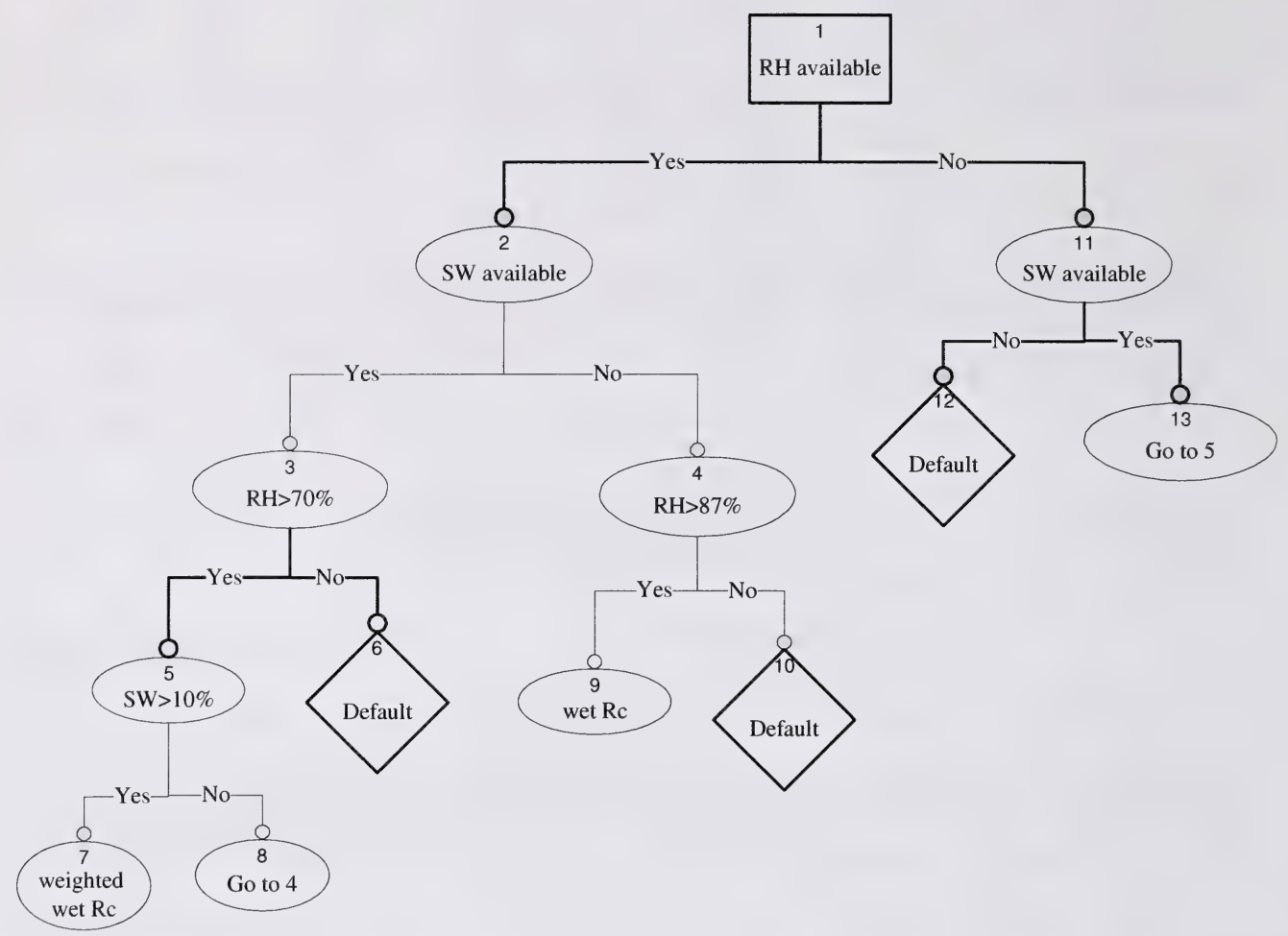

Adapted from Bates (1996)

Default $=R_{c}$ value for dry conditions

Wet $R_{c}=R_{c}$ value for wet conditions

Weighted Wet $R_{c}=$ Time weighted wet $R_{c}$

Time weighted wet $\mathbf{R}_{\mathbf{c}}=\left(\frac{S W}{100} \times\right.$ wet $\left.R c\right)+\left[\left(1-\frac{S W}{100}\right) \times \operatorname{dry} R c\right]$

\section{Calculation of $\mathrm{V}_{\mathrm{d}}$ in the absence of meteorological data:}

Missing hourly meteorological data are treated in the following manner:

- 1 hour of meteorological data missing $\rightarrow$ the average resistance of the hours before and after are used to represent the missing hour

- consecutive hours of meteorological data missing $\rightarrow$ each hour's calculated median resistance for the month is used to represent the missing hours 


\section{APPENDIX II}

\section{Environment Canada Calculation Methods for Gases and Particulates}

(after Brooks, 1999a, 199b; Zhang et al., 2003a, 2003b, 2002a, 2002b, 2001a, and 2001b)

\section{Parameters (for gases):}

$V_{d}: \quad$ deposition velocity $(\mathrm{m} / \mathrm{s})$

$R_{a}: \quad$ aerodynamic resistance $(\mathrm{s} / \mathrm{m})$

$R_{b}: \quad$ boundary-layer resistance $(\mathrm{s} / \mathrm{m})$

$R_{c}: \quad$ surface resistance $(\mathrm{s} / \mathrm{m})$

$k$ : $\quad$ von Karman constant $(0.4)$

$u *: \quad$ friction velocity $(\mathrm{m} / \mathrm{s})$

$u$ : $\quad$ horizontal wind speed at reference height $(\mathrm{m} / \mathrm{s})$

$L$ : $\quad$ Monin-Obukhov length

$H$ : $\quad$ sensible heat flux

$\mathrm{z}$ : reference height $(10 \mathrm{~m})$

$\mathrm{z}_{0}$ : $\quad$ surface roughness length $(\mathrm{m})$

$\psi_{H}: \quad$ stability function

$R i$ : Bulk Richardson number

g: $\quad$ gravitational acceleration $\left(9.81 \mathrm{~m} / \mathrm{s}^{2}\right)$

$T_{2}$ : $\quad$ temperature at reference height $\left({ }^{\circ} \mathrm{K}\right)$

$T_{2 p}$ : $\quad$ potential temperature at reference height $\left({ }^{\circ} \mathrm{K}\right)$

$T_{s}$ : $\quad$ surface temperature $\left({ }^{\circ} \mathrm{K}\right)$

$T_{d}: \quad$ temperature difference $\left({ }^{\circ} \mathrm{K}\right)$

$P: \quad$ surface pressure $(\mathrm{kPa})$

$T_{\text {avg: }} \quad$ temperature average, $T_{\text {avg }}=\left(T_{2 p}+T_{s}\right) / 2$

SR: $\quad$ solar radiation $\left(\mathrm{w} / \mathrm{m}^{2}\right)$

RH: $\quad$ relative humidity (\%)

Prec: $\quad$ precipitation ( $\mathrm{mm} /$ hour)

FCLD: $\quad$ fraction of cloud covering (\%)

$\cos \theta$ : $\quad \operatorname{cosine}$ of solar zenith angle

$\cos \alpha: \quad \quad \quad \quad \quad \quad \quad \quad 0.5$

Di: $\quad$ molecular diffusivity

Dv: $\quad$ water diffusivity

Vi: $\quad$ thermal diffusivity

$M W: \quad$ Molecular Weight, $\mathrm{MW}_{\mathrm{air}}=29$ 
$W_{\text {st: }} \quad$ fraction of stomatal blocking under wet conditions

$R_{s t}: \quad$ stomatal resistance

$R_{m}$ : mesophyll resistance (dependent only on chemical species)

$R_{a c}$ : $\quad$ in-canopy aerodynamic resistance (not chemical species-dependent)

$R_{g}$ : $\quad$ ground resistance (scaled from $\mathrm{SO}_{2}$ and $\mathrm{O}_{3}$ 's $\mathrm{R}_{\mathrm{g}}$ )

$R_{\text {cut }}: \quad$ cuticle uptake resistance (scaled from $\mathrm{SO}_{2}$ and $\mathrm{O}_{3}$ 's $\mathrm{R}_{\text {cut }}$ )

$G_{s}(P A R): \quad$ unstressed leaf stomatal conductance

PAR: $\quad$ Photosynthetic Active Radiation

$f(T)$ : $\quad$ conductance-reducing effects of air temperature T $\left({ }^{\circ} \mathrm{C}\right)$

$f(D)$ : $\quad$ conductance-reducing effects of water-vapour-pressure deficit D

D: $\quad$ water-vapour-pressure deficit

$f(\psi)$ : $\quad$ conductance-reducing effects of water stress $\psi$

$\psi$ : $\quad$ water stress

$\psi_{c 1}$ and $\psi_{c 2}$ : leaf-water-potential dependency

$E^{*}(T): \quad$ saturation water vapour pressure $(\mathrm{kPa})$ at air temperature $\mathrm{T}\left({ }^{\circ} \mathrm{K}\right)$

$E$ : $\quad$ ambient water vapour pressure $(\mathrm{kPa})$

$f_{\text {snow }}$ : $\quad$ snow cover fraction

Sd: $\quad$ snow depth (cm)

$S d_{\text {max }}$ : $\quad$ maximum snow depth $(\mathrm{cm})$

$R_{\text {cutw } 0,}$ reference values of wet cuticle resistance, see Table 1 for $R_{\text {cutw } 0}\left(\mathrm{O}_{3}\right)$

$R_{\text {cutwo }}\left(\mathrm{SO}_{2}\right): \quad 50 \mathrm{~s} / \mathrm{m}$ or $100 \mathrm{~s} / \mathrm{m}$ for rain or dew conditions, respectively

$R_{\text {cutd } 0}, \quad$ reference values of dry cuticle resistance, see Table 1

LAI: $\quad$ Leaf Area Index

LUC: $\quad$ Land Use Category (26 LUCs in gas model)

\section{Deposition Velocity:}

$V_{d}=\frac{1}{R_{a}+R_{b}+R_{c}}$

Aerodynamic Resistance (for surfaces other than water/lake):

ENVC adapts the Acid Deposition and Oxidant Model (ADOM) formulated by Pleim et. al. (1984) and further investigated by Padro et al. (1990).

$R_{a}=\frac{1}{k u_{*}}\left[0.74 \ln \left(z / z_{0}\right)-\psi_{H}\right]$, with a lower limit of 5 and upper limit of 1000 
Friction velocity:

$$
u_{*}=\left\{\begin{array}{cc}
\frac{k u}{\ln \left(\frac{z}{z 0}\right)(1+4.7 R i)} & \text { Stable, } R i>0 \\
\frac{k u}{\ln \left(\frac{z}{z 0}\right)} \sqrt{1-\frac{9.4 R i}{1+7.4\left[k / \ln \left(\frac{z}{z 0}\right)\right]^{2} \sqrt{|R i|}}} & \text { Unstable, } R i<0
\end{array}\right.
$$

\section{Stability function:}

$$
\psi_{H}=\left\{\begin{array}{cc}
-4.7 \frac{z}{L} & \text { stable, } 0<\frac{z}{L}<1 \\
0.74 \times 2 \ln \left\{\frac{1+\sqrt{1-9 \frac{z}{L}}}{2}\right\} & \text { unstable, }-1<\frac{z}{L}<0
\end{array}\right.
$$

\section{Monin-Obukhov length:}

$L=\frac{T_{a v g} u_{*}^{3}}{k H g}$, with a lower limit of -5 and upper limit of +5

\section{Bulk Richardson number:}

$R i=\frac{g z\left(T_{2 p}-T_{s}\right)}{T_{s} u^{2}}$, with a fixed value of $1 \times 10^{-15}$ if $\mathrm{SR}>0$ and $\mathrm{Ri}>0$

\section{Temperature difference:}

$T_{d}=T_{2 p}-T_{s}$, with an upper limit of $-10^{-10}$ for negative values and a lower limit of $10^{-10}$ for positive values 
Sensible heat flux:

$$
H=\left\{\begin{array}{cc}
\left\{\frac{u T_{d}}{0.74}\right\}\left\{\frac{k}{\ln (z / z 0)}\right\}^{2}\left\{\frac{1}{(1+4.7 R i)^{2}}\right\} & \text { Stable, } R i>0 \\
\left\{\frac{u T_{d}}{0.74}\right\}\left\{\frac{k}{\ln (z / z 0)}\right\}^{2}\left\{1-\frac{9.4 R i}{1+5.3[k / \ln (z / z 0)]^{2} \sqrt{|R i|}}\right\} & \text { Unstable, Ri<0 }
\end{array}\right.
$$

\section{Sub Layer Resistance:}

$$
R_{b}=\frac{5}{u_{*}}\left(\frac{V i}{D i}\right)^{2 / 3}
$$

\section{Thermal diffusivity:}

$$
V i=\frac{145.8 \times 10^{-4} T_{\text {avg }}^{3 / 2}}{T_{\text {avg }}+110.4}
$$

\section{Molecular diffusivity:}

$$
D i=\frac{0.001 T_{s}^{7 / 4} \sqrt{\frac{1}{M W_{\text {gas }}}+\frac{1}{M W_{\text {air }}}}}{\left(D_{\text {air }}^{1 / 3}+D_{\text {gas }}^{1 / 3}\right)^{2}}
$$

where,

$$
\begin{aligned}
& D_{\text {gas }}=0.369 M W_{\text {gas }}+6.29 \\
& D_{\text {air }}=0.369 M W_{\text {air }}+6.29
\end{aligned}
$$

\section{Total Surface Resistance:}

$\frac{1}{R_{c}}=\frac{1-W s t}{R_{s t}+R_{m}}+\frac{1}{R_{a c}+R_{g}}+\frac{1}{R_{c u t}}$, with a lower limit of $10 \mathrm{~s} / \mathrm{m}$ 
Fraction of stomatal blocking under wet conditions:

$$
W s t=\left\{\begin{array}{cc}
0, & S R \leq 200 \mathrm{Wm}^{-2} \\
(S R-200) / 800 & 200<S R \leq 600 \mathrm{Wm}^{-2} \\
0.5 & S R>600 \mathrm{Wm}^{-2}
\end{array}\right.
$$

\section{Stomatal resistance:}

$$
R_{s t}=\frac{1}{G_{s}(P A R) f(T) f(D) f(\psi) D_{i} / D_{v}}
$$

\section{Water diffusivity:}

$D_{v}=\frac{0.001 T_{s}^{7 / 4} \sqrt{\frac{1}{M W_{\text {water }}}+\frac{1}{M W_{\text {air }}}}}{\left(D_{\text {air }}^{1 / 3}+D_{\text {water }}^{1 / 3}\right)^{2}}$

\section{Unstressed leaf stomatal conductance:}

$$
\begin{aligned}
& G_{s}(P A R)=F_{\text {sun }} / r_{s t}\left(P A R_{\text {sun }}\right)+F_{\text {shade }} / r_{s t}\left(P A R_{\text {shade }}\right) \\
& F_{\text {sun }}=2 \cos \theta\left[1-e^{-0.5 L A l / \cos \theta}\right] \\
& F_{\text {shade }}=L A I-F_{\text {sun }} \\
& r_{s t}(P A R)=r_{s t \min }\left(1+b_{r s} / P A R\right) \\
& P A R_{\text {shade }}=\left\{\begin{array}{l}
R_{\text {diff }} e^{\left(-0.5 L A I^{0.7}\right)}+0.07 R_{\text {dir }}(1.1-0.1 L A I) e^{-\cos \theta} \quad L A I<2.5 \quad \text { or } \quad \text { SolarRad }<200 w^{-2} \\
R_{\text {diff }} e^{\left(-0.5 L A I^{0.8}\right)}+0.07 R_{\text {dir }}(1.1-0.1 L A I) e^{-\cos \theta} \quad L A I>2.5 \quad \text { and } \quad \text { SolarRad }>200 w^{-2}
\end{array}\right. \\
& P A R_{\text {sun }}=\left\{\begin{array}{lc}
R_{\text {dir }} \cos \alpha / \cos \theta+P A R_{\text {shade }} & L A I<2.5 \text { or } \quad \text { SolarRad }<200 w^{-2} \\
R_{\text {dir }}^{0.8} \cos \alpha / \cos \theta+P A R_{\text {shade }} & L A I>2.5 \text { and } \quad \text { SolarRad }>200 \mathrm{wm}^{-2}
\end{array}\right.
\end{aligned}
$$

\section{Conductance-reducing effects of air temperature $T$ :}

$$
f(T)=\frac{T-T_{\min }}{T_{o p t}-T_{\min }}\left[\frac{T_{\max }-T}{T_{\max }-T_{o p t}}\right]^{b r}
$$


where $b r=\frac{T_{\max }-T_{o p t}}{T_{o p t}-T_{\min }}$

Conductance-reducing effects of water-vapour-pressure deficit D:

$f(D)=1-b_{v p d} D$, with a lower limit of 0.1 and a upper limit of 1

Water-vapour-pressure deficit:

$D=E^{*}(T)-E$

Saturation vapor pressure:

$E^{*}(T)=0.6108 e^{\frac{17.27(T-273.16)}{T-35.86}}$

Ambient water vapour pressure:

$E=E^{*}(T) R H$

Conductance-reducing effects of water stress:

$f(\psi)=\left\{\begin{array}{cl}\left(\psi-\psi_{c s}\right) /\left(\psi_{c 1}-\psi_{c 2}\right) & \psi<\psi_{c 1} \\ 1 & \psi \geq \psi_{c 1}\end{array}\right.$

where $\psi=-0.72-0.0013 S R$, with a lower limit of 0.1 and upper limit of 1

Mesophyll resistance:

Values of $R_{m}$ for all dry-depositing species in AURAMS gas-phase chemical mechanism listed in Table 1.

In-canopy aerodynamic resistance:

$R_{a c}=\frac{R_{a c 0} L A I^{1 / 4}}{u_{*}^{2}}$

where,

$\mathrm{R}_{\mathrm{ac} 0}$ : reference value for in-canopy aerodynamic resistance (Table 1) 


\section{LAI: Leaf area index (Table 1)}

For some LUCs, a range of $R_{\mathrm{ac} 0}$ values is given to reflect the change of canopy structure at different times of the growing season. $\mathrm{R}_{\mathrm{ac} 0}$ values for any day of the year based on minimum and maximum LAI values given as:

$$
R_{a c 0}(t)=R_{a c 0}(\min )+\frac{L A I(t)-L A I(\min )}{L A I(\operatorname{Max})-L A I(\min )} \times\left[R_{a c 0}(\max )-R_{a c 0}(\min )\right]
$$

\section{Ground resistance:}

$\frac{1}{R_{g}(i)}=\frac{\alpha(i)}{R_{g}\left(S_{2}\right)}+\frac{\beta(i)}{R_{g}\left(O_{3}\right)}$

where,

$$
R_{g}\left(O_{3}\right)=\left\{\begin{array}{cc}
2000 s m^{-1} & \text { LUC } 1-3 \text { and Snow Surface } \\
200 \mathrm{~s} \mathrm{~m}^{-1} & \text { LUC } 4-19,25 \text { and } 26 \\
500 \mathrm{~s} \mathrm{~m}^{-1} & \text { LUC } 20-24
\end{array}\right.
$$

For snow surface, $\mathrm{R}_{\mathrm{g}}\left(\mathrm{O}_{3}\right)$ adjusted by including a snow cover fraction $\left(f_{\text {snow }}\right)$ :

$$
\frac{1}{R_{g}\left(O_{3}\right)}=\frac{1-2 f_{\text {snow }}}{R_{g}(L U C)}+\frac{2 f_{\text {snow }}}{R_{\text {snow }}}
$$

where,

$$
f_{\text {snow }}=\frac{s d}{s d_{\max }} \text {, note - both } f_{\text {snow }} \text { and } 2 f_{\text {snow }} \text { have a lower limit of } 0 \text { and upper }
$$

limit of 1

$$
R_{\text {snow }}=2000 \mathrm{~s} / \mathrm{m}
$$

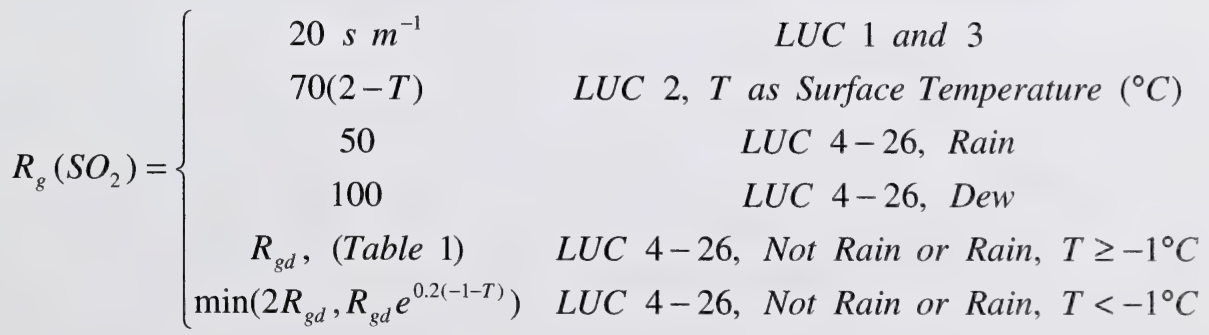


with a lower limit of $100 \mathrm{~s} / \mathrm{m}$ and upper limit of $500 \mathrm{~s} / \mathrm{m}$

For snow surface, $\mathrm{R}_{\mathrm{g}}\left(\mathrm{SO}_{2}\right)$ are adjusted by snow cover fraction $\left(f_{\text {snow }}\right)$ :

$$
\frac{1}{R_{g}\left(\mathrm{SO}_{2}\right)}=\frac{1-2 f_{\text {snow }}}{R_{g}(L U C)}+\frac{2 f_{\text {snow }}}{R_{\text {snow }}}
$$

where,

$f_{\text {snow }}=\frac{s d}{s d_{\text {max }}}$, note - both $f_{\text {snow }}$ and $2 f_{\text {snow }}$ have a lower limit of 0 and upper limit of 1

$$
R_{\text {snow }}=70(2-T), \mathrm{T} \text { as }{ }^{\circ} \mathrm{C}
$$

\section{Canopy cuticle resistance:}

$$
R_{\text {cut }}=\left\{\begin{array}{cc}
\frac{R_{\text {cutw } 0}}{L A I^{1 / 2} u_{*}} & \text { Rain or Dew } \\
\frac{R_{\text {cutd } 0}}{e^{0.03 R H} L A I^{1 / 4} u_{*}} & \text { Not Rain } \\
\min \left(2 R_{\text {cut }}, R_{\text {cut }} e^{0.2(-1-T)}\right) & T<-1^{\circ} C
\end{array}\right.
$$

where,

$\mathrm{R}_{\text {cutwo }}\left(\mathrm{O}_{3}\right)$ listed in Table 1.

$\mathrm{R}_{\text {cutw0 }}\left(\mathrm{SO}_{2}\right)=50 \mathrm{~s} / \mathrm{m}$ or $100 \mathrm{~s} / \mathrm{m}$ for rain or dew conditions, respectively.

$\mathrm{R}_{\text {cutdo }}$ listed in Table 1 .

with a lower limit of $100 \mathrm{~s} / \mathrm{m}$ and $20 \mathrm{~s} / \mathrm{m}$ for $\mathrm{SO}_{2}$ dry and wet conditions, respectively

For snow surface, $\mathbf{R}_{\text {cut }}$ are adjusted by including a snow cover fraction $\left(f_{\text {snow }}\right)$

$\frac{1}{R_{\text {cut }}}=\frac{1-f_{\text {snow }}}{R_{\text {cut }}}+\frac{f_{\text {snow }}}{R_{\text {snow }}}$

where

$$
R_{\text {snow }}=\left\{\begin{array}{cc}
2000 & O_{3} \\
70(2-T) & \mathrm{SO}_{2}
\end{array}\right.
$$




\section{Roughness length:}

$z_{0}(t)=z_{0}(\min )+\frac{L A I(t)-L A I(\min )}{L A I(\operatorname{Max})-L A I(\min )} \times\left[z_{0}(\max )-z_{0}(\min )\right]$

\section{Rain or Dew conditions:}

Condition $=\left\{\begin{array}{cc}\text { Rain } & T>273.15^{\circ} \mathrm{K} \text { and } \operatorname{Pr} e c .>0.1 \mathrm{~mm} / \mathrm{hr} \\ \text { Dew } & T>273.15^{\circ} \mathrm{K} \text { and } u^{*} .>u^{*}{ }_{\text {min }}\end{array}\right.$

where:

$$
u_{\min }^{*}=\frac{1.5 \text { Coedew }}{D Q}
$$

where:

$$
\text { Coedew }=\left\{\begin{array}{cc}
0.3 & F C L D<0.25 \\
0.2 & 0.25 \leq F C L D<0.75 \\
0.1 & 0.75 \leq F C L D \leq 1
\end{array}\right.
$$

and

$D Q=0.0622(1-R H) E^{*}\left(T_{s}\right)$, with a lower limit of 0.0001 


\section{Parameters (for particulates):}

(Variables for computing $R_{a}$ were not included)

$V_{d}: \quad$ deposition velocity $(\mathrm{m} / \mathrm{s})$

$R_{a}: \quad$ aerodynamic resistance $(\mathrm{s} / \mathrm{m})$

$R_{s}: \quad \quad$ surface resistance $(\mathrm{s} / \mathrm{m})$

$u *: \quad$ friction velocity $(\mathrm{m} / \mathrm{s})$

$u: \quad$ horizontal wind speed at reference height $(\mathrm{m} / \mathrm{s})$

g: $\quad$ gravitational acceleration $\left(9.81 \mathrm{~m} / \mathrm{s}^{2}\right)$

$T_{2}$ : $\quad$ temperature at reference height $\left({ }^{\circ} \mathrm{K}\right)$

LAI: $\quad$ Leaf Area Index

LUC: $\quad$ Land Use Category (15 LUCs in particle model)

$S C: \quad$ Season Category (5 SCs in particle model, listed in Table 5)

$\rho: \quad$ density of particle

$d p: \quad$ particle diameter

C: $\quad$ correction factor for small particles

$\mu$ : dynamic viscosity of air

$v: \quad$ kinematic viscosity of air

C: $\quad$ Cunningham slip correction factor

$\mathrm{E}_{\mathrm{B}}$ : collection efficiency from Brownian diffusion

$\mathrm{E}_{\mathrm{IM}}$ : collection efficiency from impaction

$\mathrm{E}_{\mathrm{IN}}$ : $\quad$ collection efficiency from interception

R1: correction factor representing fraction of particles that sticks to surface

Sc: $\quad$ Schmidt number

D: $\quad$ Brownian diffusivity

St: $\quad$ Stokes number

$K: \quad$ Boltzmann constant $\left(\mathrm{gm} \mathrm{cm}^{2} / \mathrm{s}^{2}-{ }^{\circ} \mathrm{K}\right)$

$P: \quad$ surface pressure $(\mathrm{kPa})$

$\lambda: \quad$ mean free path of air molecules

\section{Deposition Velocity:}

$V_{d}=V_{g}+\frac{1}{R_{a}+R_{s}}$

Assumes $\mathrm{SO}_{4}{ }^{2-}$ and $\mathrm{NH}_{4}{ }^{+}$have the same $\mathrm{V}_{\mathrm{d}}$; and $\mathrm{NO}_{3}{ }^{-}, \mathrm{Ca}^{2+}, \mathrm{Mg}^{2+}, \mathrm{Na}^{+}$, and $\mathrm{K}^{+}$have the same $\mathrm{V}_{\mathrm{d}}$ as described in Cheng et al. (2001). 
Mass median diameter (MMD) and geometric standard deviation (GSD) for $\mathrm{SO}_{4}{ }^{2-}$ chosen as $0.35 \mu \mathrm{m}$ and $2.0 \mu \mathrm{m}$, respectively as reported in Wesely et al. (1985).

MMD and GSD for $\mathrm{Na}^{+}$are taken as $5.12 \mu \mathrm{m}$ and $2.64 \mu \mathrm{m}$, respectively as reported in Ruijgrok et al (1997).

\section{Gravitational settling velocity:}

$V_{g}=\frac{\rho d_{p}^{2} g C}{18 \mu}$

\section{Cunningham slip correction factor:}

$$
C=1+\frac{2 \lambda}{d_{p}}\left(1.257+0.4 e^{-0.55 d_{p} / \lambda}\right)
$$

\section{Aerodynamic Resistance:}

$\mathrm{R}_{\mathrm{a}}$ is computed with the same approach as the gas model, but the parameters are adapted from Table 4.

\section{Surface Resistance:}

$$
R_{s}=\frac{1}{\varepsilon_{0} u_{*}\left(E_{B}+E_{I M}+E_{I N}\right) R_{1}} \text {, with a lower limit of } 5
$$

where $\varepsilon_{0}$ is an empirical constant chosen as 3 for all LUCs

\section{Collection efficiency from Brownian diffusion:}

$$
E_{B}=S c^{-\gamma}
$$

where $\gamma$ lies between $1 / 2$ and $2 / 3$ with larger values for rougher surfaces. (Table 4 )

\section{Schmidt number:}

$$
S c=v / D
$$


Collection efficiency from impaction:

$E_{I M}=\left(\frac{S t}{\alpha+S t}\right)^{\beta}$

where,

a: constant varying with LUC (Table 4)

b: constant, chosen as 2

Stokes number:

$S t=\left\{\begin{array}{l}\frac{V_{g} u_{*}^{2}}{v} \quad \text { smooth surface, LUC8, 9, 12, 13, and } 14 \\ \frac{V_{g} u_{*} A}{g} \quad \text { vegetated surface, LUCs other than above }\end{array}\right.$

where A is the characteristic radius varying with LUC and season (Table 4)

Collection efficiency from interception:

$E_{I N}=\frac{1}{2}\left(\frac{d_{p}}{A}\right)^{2}$, with a upper limit of 0.6

where A is the characteristic radius varying with LUC and season (Table 4)

Correction factor representing fraction of particles that sticks to the surface:

$R_{1}=\exp \left(-S t^{1 / 2}\right)$, with a low limit of 0.5

Mean free path of air molecules:

$\lambda=6.54 \times 10^{-8} \frac{\mu}{1.818 \times 10^{-5}} \frac{101.3}{P}\left(\frac{T_{2}}{293.15}\right)^{1 / 2}$

Brownian diffusivity:

$D=\frac{C K T_{2}}{3 \pi d_{p} \mu}$ 
Dynamic viscosity of air:

$\mu=\frac{145.8 \times 10^{-8} T_{2}^{3 / 2}}{T_{2}+110.4}$

Kinematic viscosity of air:

$v=\frac{\mu}{\rho_{\text {air }}}$ 


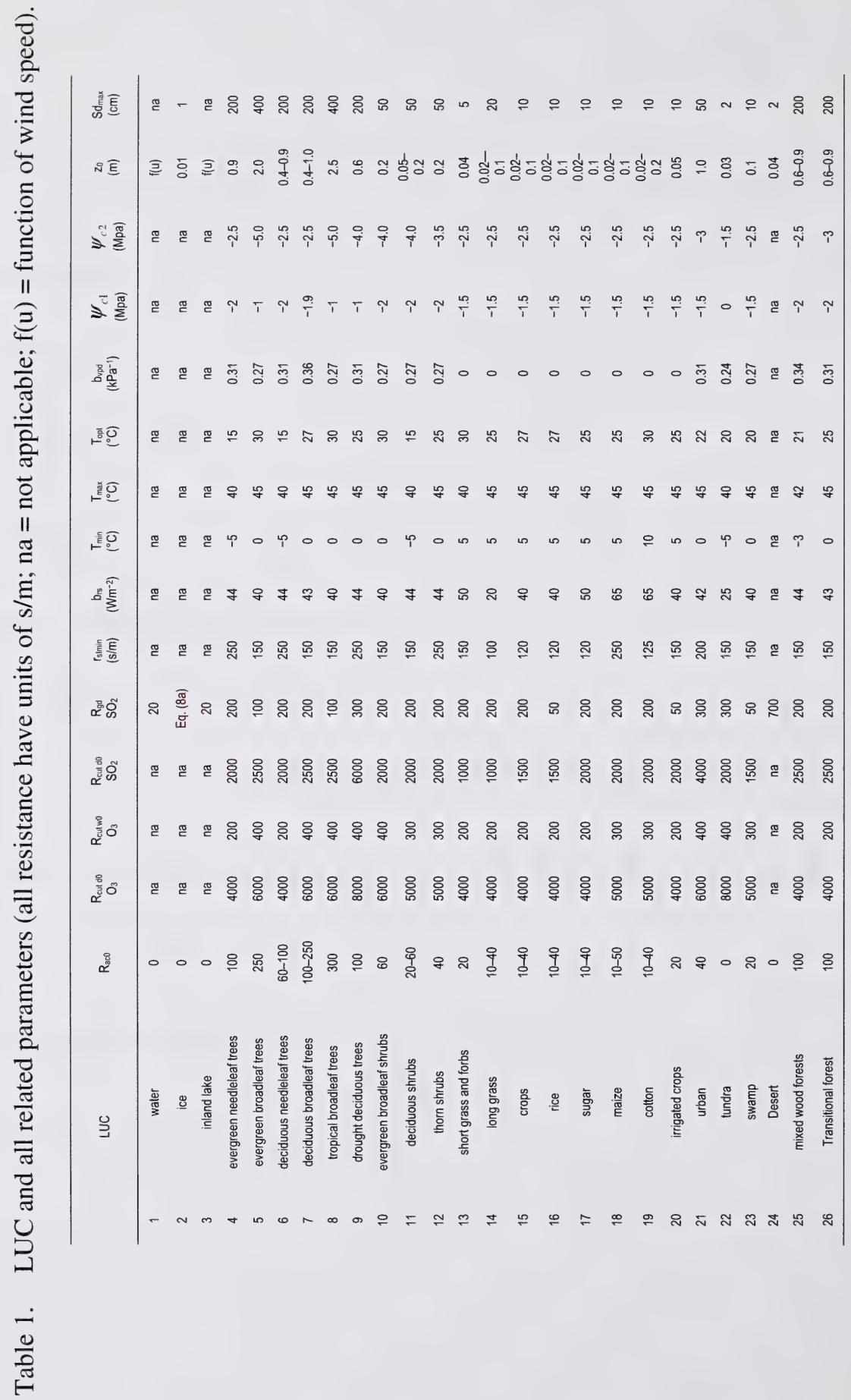




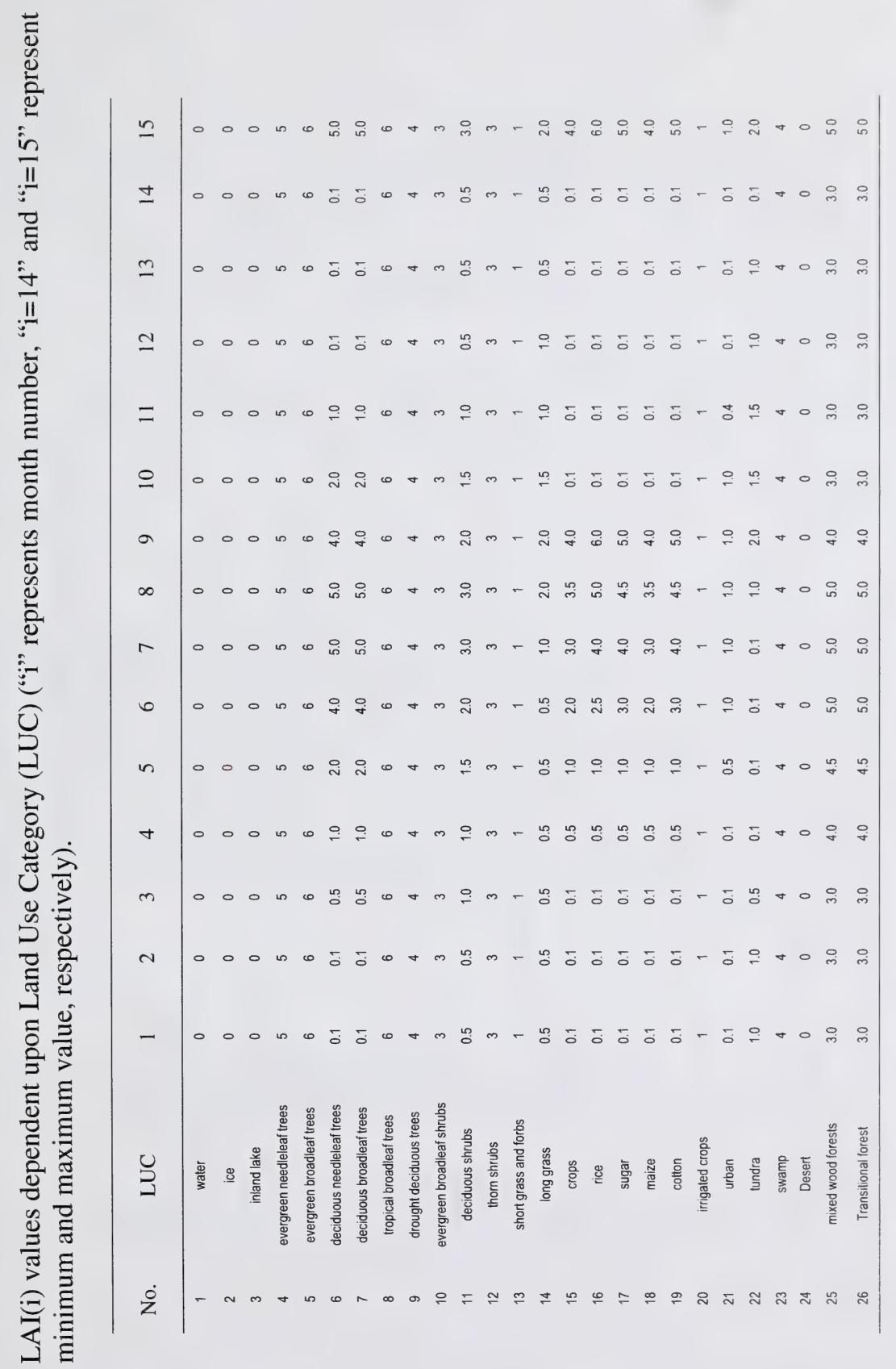

$\frac{2}{\frac{0}{0}}$ 


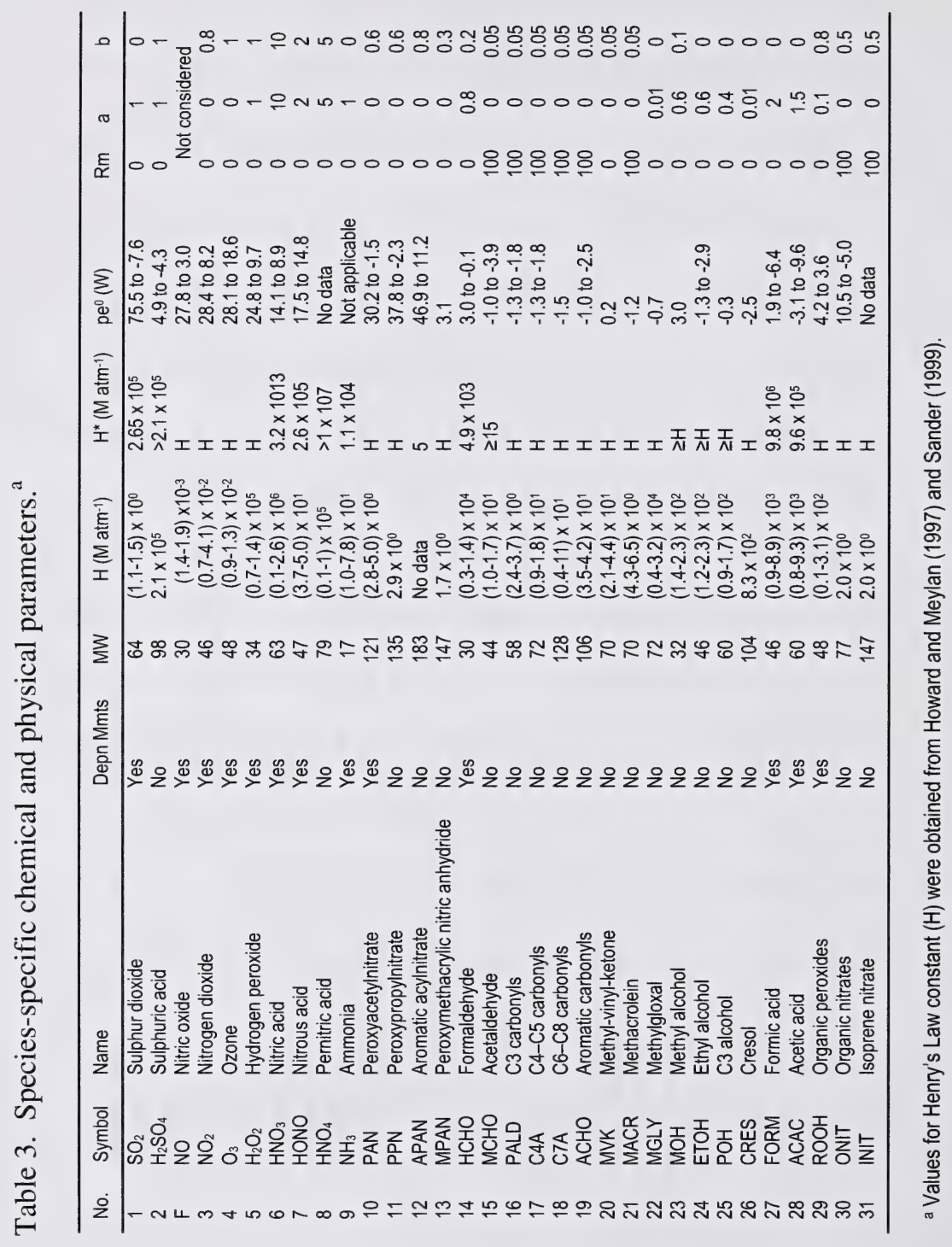




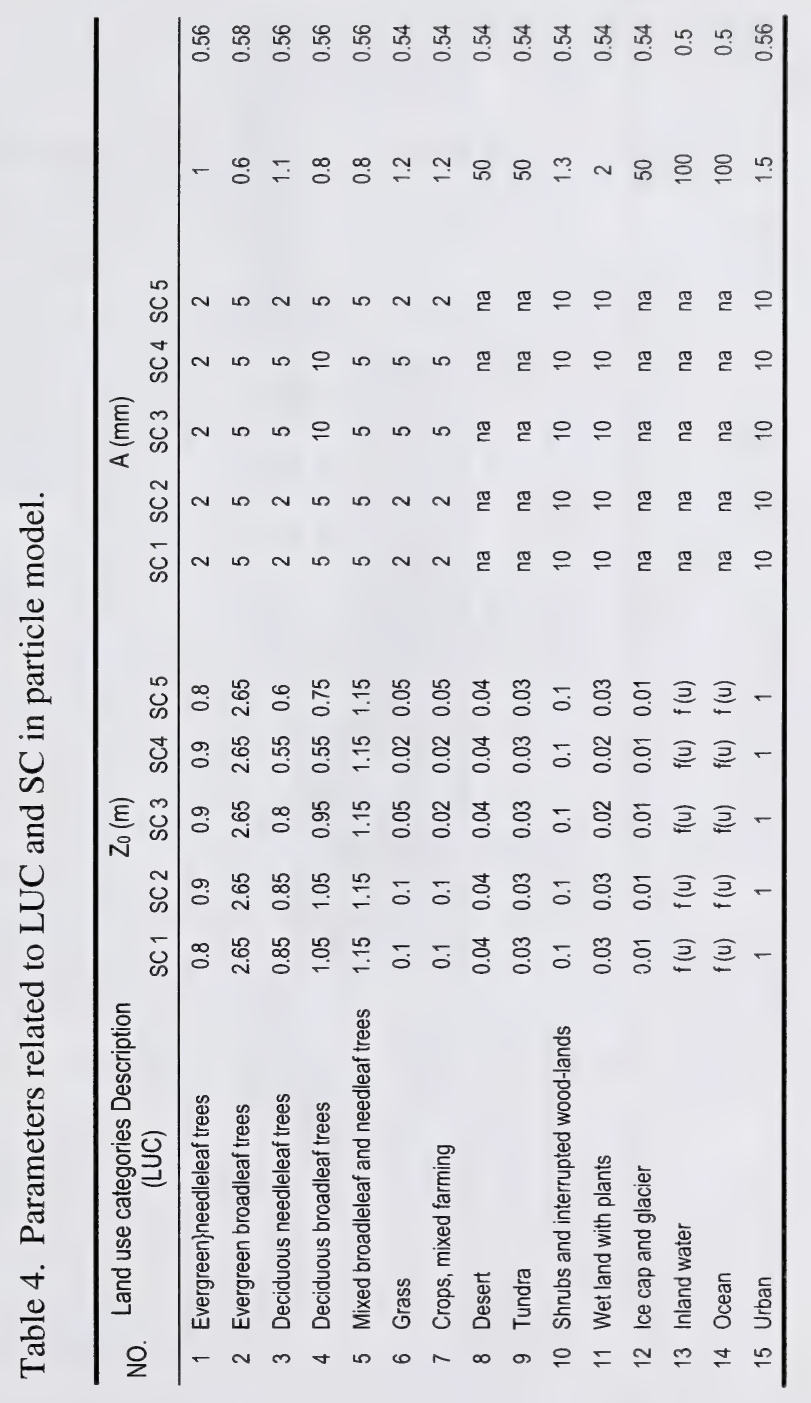




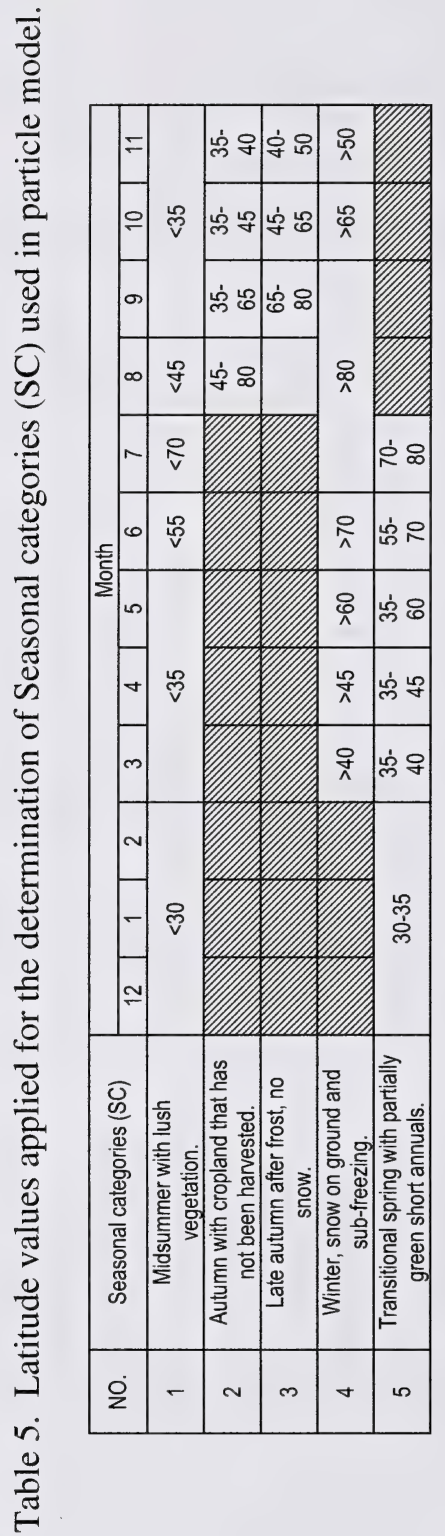




\section{APPENDIX III}

\section{WBEA Dry Deposition Calculation Methods for Gases $\left(\mathrm{SO}_{2}\right.$ and $\left.\mathrm{NO}_{2}\right)$}

(after EPCM, 2002, 2000)

\section{Parameters:}

$V_{d}: \quad$ deposition velocity $(\mathrm{m} / \mathrm{s})$

$R_{a}: \quad$ aerodynamic resistance $(\mathrm{s} / \mathrm{m})$

$R_{b}: \quad$ boundary-layer resistance $(\mathrm{s} / \mathrm{m})$

$R_{c}: \quad$ surface resistance $(\mathrm{s} / \mathrm{m})$

$\theta: \quad$ standard deviation of wind direction ( $\mathrm{rad})$

$u *: \quad$ friction velocity $(\mathrm{m} / \mathrm{s})$

$u: \quad$ horizontal wind speed at reference height $(\mathrm{m} / \mathrm{s})$

SR: $\quad$ solar radiation $\left(\mathrm{w} / \mathrm{m}^{2}\right)$

SW: $\quad$ surface wetness

\section{Deposition Velocity:}

$\mathbf{V}_{\mathbf{d}}=\frac{1}{\left(R_{a}+R_{b}+R_{c}\right)}$

\section{Aerodynamic Resistance:}

$R_{a}= \begin{cases}\frac{4}{u \theta^{2}} & \text { Stable conditions, night time }\left(S R \leq 5 \mathrm{w} / \mathrm{m}^{2}\right) \text { or } \theta<0.2 \mathrm{rad} \\ \frac{9}{u \theta^{2}} & \text { Unstable conditions, day time }\left(S R>5 \mathrm{w} / \mathrm{m}^{2}\right) \text { and } \theta>0.2 \mathrm{rad}\end{cases}$

- with an upper limit of 1000

$-\mathrm{u}$ has a lower limit of $0.36 \mathrm{~m} / \mathrm{s}$

\section{Boundary-Laver Resistance for $\mathrm{SO}_{2}$ :}

$R_{b}=\frac{7.225}{u^{*}}$

- with an upper limit of 1000 , where $u^{*}=\left(\frac{u}{R_{a}}\right)^{0.5}$ 


\section{Boundary-Laver Resistance for $\mathrm{NO}_{2}$ :}

$\mathrm{R}_{\mathrm{b}}=\frac{6.18}{u^{*}}$

\section{Surface Resistance:}

Same as Alberta Environment method (Appendix I), where dry/wet conditions determined by SW:

SW $>0.1$, wet conditions

$\mathrm{SW} \leq 0.1$, dry conditions 


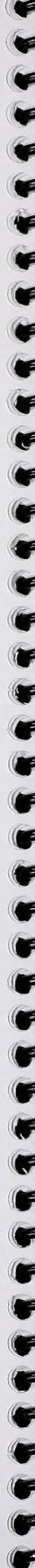




LIBRARY AND ARCHIVES CANADA
Bibliothèque et Archives Canada

33286541215840 